\title{
The Surface Chemistry of Propylene, 1-Iodopropane, and 1,3-Diiodopropane on MoAl Alloy Thin Films Formed on Dehydroxylated Alumina
}

\author{
Feng Gao, Yilin Wang, and W. T. Tysoe* \\ Department of Chemistry and Biochemistry, and Laboratory for Surface Studies, \\ University of Wisconsin-Milwaukee, Milwaukee, Wisconsin 53211
}

Received: January 10, 2006; In Final Form: March 27, 2006

\begin{abstract}
The adsorption of $\mathrm{C}_{3}$ hydrocarbons propylene, 1-iodopropane, and 1,3-diiodopropane is studied in ultrahigh vacuum on a molybdenum-aluminum alloy formed by molybdenum hexacarbonyl reaction with a planar alumina film grown on a $\mathrm{Mo}(100)$ substrate. Carbon-iodine bond scission occurs below $\sim 200 \mathrm{~K}$ to deposit iodine, and form propyl species from 1-iodopropane and a $\mathrm{C}_{3}$ metallacycle from 1,3-diiodopropane. Propyl species either undergo $\beta$-hydride elimination to yield propylene or hydrogenate to form propane. Propylene adsorbs as both $\pi$ - and di- $\sigma$-bonded species, and the di- $\sigma$ form hydrogenates to yield propane, where the addition of the first hydrogen to form propyl species is slower than the second hydrogenation step to yield propane. Propylene also thermally decomposes on the surface to desorb hydrogen and deposit carbon where the methylyne group is the most, and the methyl group the least reactive. The metallacyclic intermediate reacts to give an allylic intermediate, which forms propylene, but also decomposes by $\mathrm{C}-\mathrm{C}$ bond cleavage to evolve ethylene and deposit methylene species on the surface. This is a key step in the mechanism proposed for heterogeneously catalyzed olefin metathesis and this is the first time that this chemistry has been directly identified in ultrahigh vacuum.
\end{abstract}

\section{Introduction}

$\mathrm{Mo}(\mathrm{CO})_{6}$ has been extensively used as a catalyst precursor ${ }^{1-12}$ and more recently to generate model catalysts grown on planar alumina thin films in ultrahigh vacuum, where surface-sensitive analytical techniques can be used. ${ }^{13-16}$ Our recent studies have shown that reacting $\mathrm{Mo}(\mathrm{CO})_{6}$ with aluminum ${ }^{17}$ and dehydroxylated and hydroxylated alumina ${ }^{18,19}$ thin films at $700 \mathrm{~K}$ deposits molybdenum carbide incorporating a small amount of oxygen. Reaction of low exposures of $\mathrm{Mo}(\mathrm{CO})_{6}$ with an alumina thin film results in the formation of small molybdenum carbide particles on the surface, while higher exposures $(\sim 5000 \mathrm{~L}$ of $\left.\mathrm{Mo}(\mathrm{CO})_{6}\right)$ lead to a thin carbide film that completely covers the surface. ${ }^{18}$ Annealing these films to $\sim 1500 \mathrm{~K}$ causes $\mathrm{CO}$ desorption through alumina reduction by the carbidic carbon, and results in MoAl alloy film formation. ${ }^{17-19}$

Recently, studies of the chemistry of $\mathrm{CH}_{3} \mathrm{I}^{20} \mathrm{CH}_{2} \mathrm{I}_{2},{ }^{21}$ and ethylene and $\mathrm{C}_{2} \mathrm{H}_{5} \mathrm{I}^{22}$ on the $\mathrm{MoAl}$ alloy surface in ultrahigh vacuum showed that besides hydrogenation, dehydrogenation, and dissociation, extensive methylene migratory insertion ${ }^{20,21}$ and $\mathrm{H}-\mathrm{D}$ exchange reactions ${ }^{20-22}$ occurred. It appears that the catalytic properties of the alloy are different from metallic molybdenum, but rather similar to those of late transition metals. This has been rationalized by electronic effects where molybdenum gains electrons by alloying with aluminum.

Since MoAl alloy surfaces are extremely effective for methylene insertion into surface-carbon single bonds to form higher, singly bonded metal-alkyl groups, ${ }^{20,21}$ this implies that they may also be similarly active for methylene insertion into the carbon-surface bond of di- $\sigma$ bonded olefin species to yield metallacycles. Metallacycles have been proposed to be the central intermediates in olefin metathesis catalysis, where the

* To whom correspondence should be addressed. Phone: (414) 2295222. Fax: (414) 229-5036. E-mail: wtt@uwm.edu. reverse of the insertion reaction forms metathesis products. Such a mechanism was first proposed by Hérisson and Chauvin, ${ }^{23}$ and was recently confirmed in ultrahigh vacuum on model molybdenum carbide catalysts. ${ }^{24}$ As a precursor to studying the metathesis chemistry, we focus here on the surface chemistry of propylene, 1-iodopropane, and 1,3-diiodopropane (DIP) to investigate the behavior of $\mathrm{C}_{3}$ species, as a prerequisite to understanding the metallacycle formation pathway.

The formation and characterization of MoAl alloy films has been extensively described. ${ }^{18}$ Briefly, they are formed by adsorbing $5000 \mathrm{~L}$ of $\mathrm{Mo}(\mathrm{CO})_{6}$ at $700 \mathrm{~K}$ onto a dehydroxylated alumina film grown on a $\mathrm{Mo}(100)$ substrate to generate a molybdenum carbide film. This is then annealed to $1500 \mathrm{~K}$ to generate a surface MoAl alloy. Alloy formation is confirmed by X-ray photoelectron and Auger spectroscopies where it is found that the binding energy of the deposited molybdenum, following annealing, is lower than that of pure metallic molybdenum. ${ }^{17,18}$ The thickness of the alloy film, based on Auger electron probe depth analysis, is estimated to be 3-4 atomic layers $^{22}$ with a $\mathrm{Mo} / \mathrm{Al}$ atomic ratio of $\sim 1.6$.

\section{Experimental Section}

Temperature-programmed desorption (TPD) data were collected in an ultrahigh vacuum chamber operating at a base pressure of $8 \times 10^{-11}$ Torr that has been described in detail elsewhere ${ }^{13,17,18}$ where desorbing species were detected with a Dycor quadrupole mass spectrometer placed in the line of sight of the sample. Temperature-programmed desorption spectra were collected at a heating rate of $10 \mathrm{deg} / \mathrm{s}$. This chamber was also equipped with a double-pass, cylindrical-mirror analyzer for Auger spectroscopy, where the spectra are typically collected by using an electron beam energy of $3 \mathrm{keV}$ and the first derivatives are obtained by numerical differentiation. 
X-ray photoelectron spectra (XPS) were collected in another chamber operating at a base pressure of $2 \times 10^{-10}$ Torr, which was equipped with an X-ray source and double-pass cylindrical mirror analyzer. Spectra were typically collected with an $\mathrm{Mg}$ $\mathrm{K} \alpha \mathrm{X}$-ray power of $250 \mathrm{~W}$ and a pass energy of $50 \mathrm{eV}$. The alumina substrate was sufficiently thin that no charging effects were found and the binding energies were calibrated by using the Mo $3 \mathrm{~d}_{5 / 2}$ feature (at $227.4 \mathrm{eV}$ binding energy) as a standard. ${ }^{17,18}$ Temperature-dependent XP and Auger spectra were collected by heating the sample to the indicated temperature for $5 \mathrm{~s}$, allowing it to cool to $150 \mathrm{~K}$, following which the spectrum was recorded.

Infrared data were collected with a Bruker Equinox infrared spectrometer equipped with a liquid nitrogen cooled, mercury cadmium telluride detector operated at $4 \mathrm{~cm}^{-1}$ resolution and data were typically collected for 1000 scans. The complete light path was enclosed and purged with dry, $\mathrm{CO}_{2}$-free air. ${ }^{15,16}$

The Mo(100) substrate ( $1 \mathrm{~cm}$ diameter, $0.2 \mathrm{~mm}$ thick) was cleaned by using a standard procedure, which consisted of argon ion bombardment $\left(2 \mathrm{kV}, 1 \mu \mathrm{A} / \mathrm{cm}^{2}\right)$, and any residual contaminants were removed by briefly heating to $2000 \mathrm{~K}$ in vacuo. The resulting Auger spectrum showed no contaminants. Aluminum was deposited onto $\mathrm{Mo}(100)$ from a small heated alumina tube, which was enclosed in a stainless steel shroud to minimize contamination of other parts of the system. ${ }^{25}$ The alumina thin film is formed by cycles of aluminum deposition-water vapor oxidation-annealing, until the Mo(100) XPS or Auger features are completely obscured, ${ }^{18}$ yielding a film thickness of $\sim 2 \mathrm{~nm}$.

Molybdenum hexacarbonyl (Aldrich, 99\%), propylene (Matheson, 99.5\%), $d_{6}$-propylene, $\mathrm{CD}_{2}=\mathrm{CH}-\mathrm{CH}_{3}, \mathrm{CH}_{2}=\mathrm{CH}-\mathrm{CD}_{3}$ (Cambridge Isotope, $\geq 99 \%$ D), 1-iodopropane, and 1,3-diiodopropane (Aldrich, 99\%) were transferred to glass vials, connected to the gas-handling line of the chamber, and purified by repeated freeze-pump - thaw cycles, followed by distillation, and their purities were monitored by mass spectroscopy. These were dosed onto the surface via a capillary doser to minimize background contamination. The exposures in Langmuirs $(1 \mathrm{~L}$ $=1 \times 10^{-6}$ Torr s) are corrected by using an enhancement factor determined by temperature-programmed desorption (see ref 13 for a more detailed description of this procedure). $\mathrm{H}_{2}$ and $\mathrm{D}_{2}$ (Matheson, $\geq 99.5 \%$ ) were used without further purification.

\section{Results}

3.1. Propylene on a MoAl Alloy. The surface chemistry of propylene on a MoAl alloy surface was investigated with temperature-programmed desorption (TPD). Figure 1 displays a number of TPD profiles as a function of propylene exposure, monitoring desorption at $42\left(\mathrm{C}_{3} \mathrm{H}_{6}\right), 2\left(\mathrm{H}_{2}\right), 16\left(\mathrm{CH}_{4}\right)$, and 29 $\left(\mathrm{C}_{3} \mathrm{H}_{8}\right)$ amu. As shown in Figure 1a, essentially no propylene desorption is found at an exposure of $0.2 \mathrm{~L}$, suggesting complete dissociation of adsorbed propylene. At a propylene exposure of $0.5 \mathrm{~L}$, two weak desorption peaks are found at $\sim 210$ and $\sim 340 \mathrm{~K}$, respectively. At an exposure of $1 \mathrm{~L}$, the intensity of both states increases, and the desorption temperature of the lowtemperature state decreases to $\sim 195 \mathrm{~K}$. Upon further increasing the exposure to $2 \mathrm{~L}$, an extra low-temperature state develops at $\sim 175 \mathrm{~K}$, and the desorption temperature maximum of the hightemperature state also decreases. The intensity of the $175 \mathrm{~K}$ state continues to increase at higher exposures and saturates at a propylene exposure of $\sim 7.5 \mathrm{~L}$ (not shown). Figure $1 \mathrm{~b}$ depicts the $\mathrm{H}_{2}$ desorption profiles. At the lowest propylene exposure $(0.2 \mathrm{~L}), \mathrm{H}_{2}$ desorbs at $\sim 390 \mathrm{~K}$. The $\mathrm{H}_{2}$ yield increases with increasing propylene exposure, accompanied by a desorption temperature decrease. At propylene exposures of $2 \mathrm{~L}$ and above, the $\mathrm{H}_{2}$ yield saturates and the desorption temperature remains constant at $\sim 370 \mathrm{~K}$. The hydrogen desorption profile following hydrogen adsorption on the MoAl alloy resembles that shown in Figure 1b, indicating that propylene has decomposed at lower temperatures. Note that the 2-amu signal below $200 \mathrm{~K}$ at propylene exposures of $2 \mathrm{~L}$ and above is due to fragmentation of molecular propylene. Shown in Figure 1c, at propylene exposures from 2 to $7.5 \mathrm{~L}$, weak yet detectable methane desorption is found at $\sim 325 \mathrm{~K}$ and this increases to $\sim 350 \mathrm{~K}$ at a propylene exposure of $10 \mathrm{~L}$. The 16-amu signal at low temperatures is due to fragmentation of molecular propylene and CO contaminant. Figure 1d plots the 29-amu (propane) desorption profiles, which is a very weak fragment of propylene but the most intense for propane so that these traces represent predominantly propane desorption. It is found, at propylene exposures of 0.5 and $1 \mathrm{~L}$, that weak yet detectable desorption appears at $\sim 250 \mathrm{~K}$. At propylene exposures of 2 and $5 \mathrm{~L}$, the intensity of this desorption state increases and the desorption peak maximum also increases slightly to $\sim 270 \mathrm{~K}$. Apparently, this desorption state is due to propylene self-hydrogenation where surface hydrogen originates from propylene dissociation and background $\mathrm{H}_{2}$ adsorption. Meanwhile, sharp features appear below $200 \mathrm{~K}$ at propylene exposures of $1 \mathrm{~L}$ and above. Since the desorption temperature and line-shape of this state resemble that of the 42 amu state (Figure 1a), it is assigned to fragmentation of the parent molecule. As will be shown below, no propane formation occurs at this temperature.

It appears that two propylenic species form on the alloy surface, one that desorbs at below $200 \mathrm{~K}$, and another that persists to much higher temperatures (Figure 1a). To establish the nature of these two species, reflection-absorption infrared spectroscopy (RAIRS) experiments were conducted and the results are displayed in Figure 2, where $10 \mathrm{~L}$ of propylene was adsorbed on the alloy surface at $80 \mathrm{~K}$, and subsequently annealed to higher temperatures. Following each annealing step, the sample was allowed to cool to $80 \mathrm{~K}$ before each spectrum was taken. It should be mentioned that propylene has a number of infrared modes below $1000 \mathrm{~cm}^{-1}$, especially the generally most intense $v\left(\mathrm{C}-\mathrm{CH}_{3}\right)$ mode at $\sim 910 \mathrm{~cm}^{-1}$. Unfortunately, these are obscured by an intense alumina LO mode. ${ }^{26,27}$ Following adsorption at $80 \mathrm{~K}$, features at 3072, 3056, 2977, and $2940 \mathrm{~cm}^{-1}$ are found in the $\mathrm{C}-\mathrm{H}$ stretching region. In the low-frequency region, relatively intense modes are detected at 1645,1452 , and $1435 \mathrm{~cm}^{-1}$. Comparing these features with solid/gas-phase propylene (Table $1^{28,29}$ ) immediately suggests that at least a portion of the adsorbed propylene adopts a $\pi$-bonded conformation on the surface at $80 \mathrm{~K}$. Annealing to $150 \mathrm{~K}$ causes the disappearance of the $3072-$ and $3056-\mathrm{cm}^{-1}$ features and a drastic attenuation of the $2977-\mathrm{cm}^{-1}$ peak, indicating the desorption of $\pi$-bonded propylene. The $\mathrm{C}=\mathrm{C}$ vibrational mode at 1645 $\mathrm{cm}^{-1}$ is still detectable, suggesting a portion of $\pi$-bonded propylene still stays on the surface. In the meantime, the relative intensity of the $1435-\mathrm{cm}^{-1}$ feature increases compared with that at $1452 \mathrm{~cm}^{-1}$. Annealing to $180 \mathrm{~K}$ substantially decreases the intensity of the $\mathrm{C}=\mathrm{C}$ vibrational mode, and results in a further increase in intensity of the $1435-\mathrm{cm}^{-1}$ feature compared to that at $1452 \mathrm{~cm}^{-1}$. On heating to $200 \mathrm{~K}$, the only detectable features are a $\mathrm{C}-\mathrm{H}$ stretching mode at $\sim 2923 \mathrm{~cm}^{-1}$ and a $\mathrm{CH}_{2}$ deformation mode at $\sim 1433 \mathrm{~cm}^{-1}$, which are assigned to di$\sigma$-bonded propylene. ${ }^{30,31}$ No features are detected above the noise level at $220 \mathrm{~K}$ and higher. Experiments were also performed by adsorbing propylene on the alloy surface at 300 $\mathrm{K}$ and no detectable features were found (not plotted), indicating 
(a)

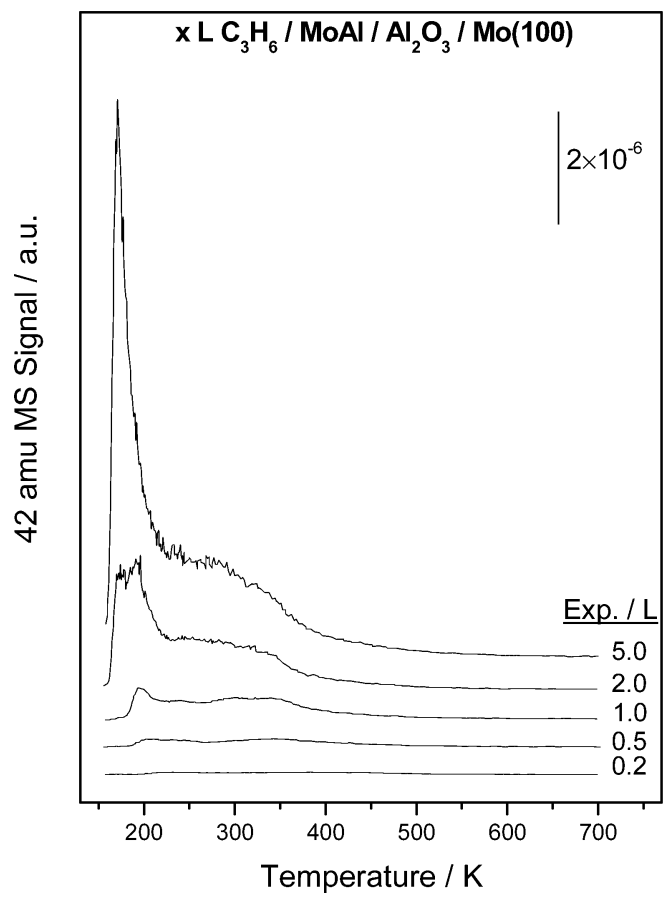

(c)

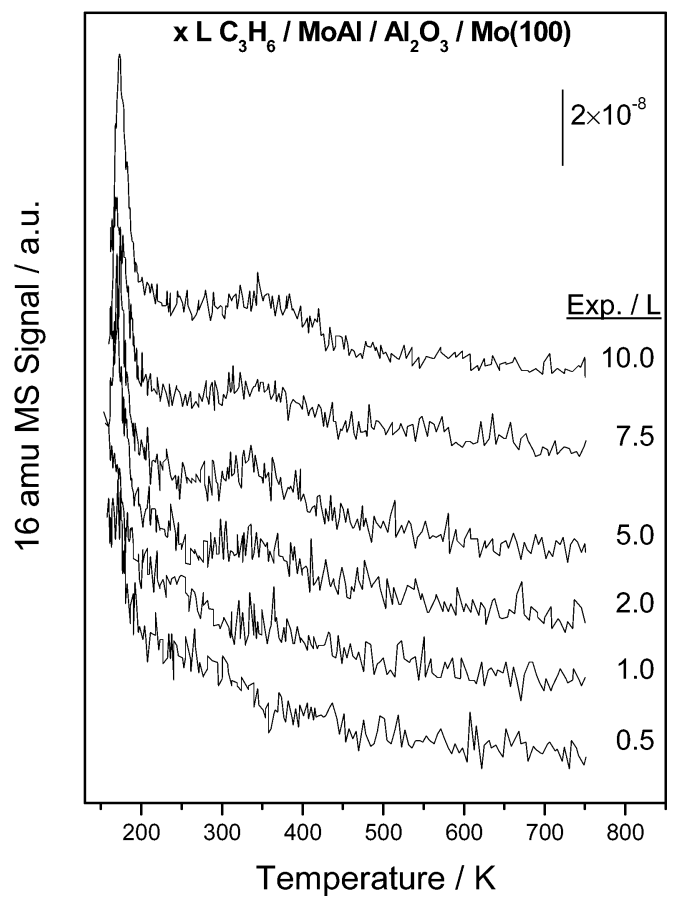

(b)

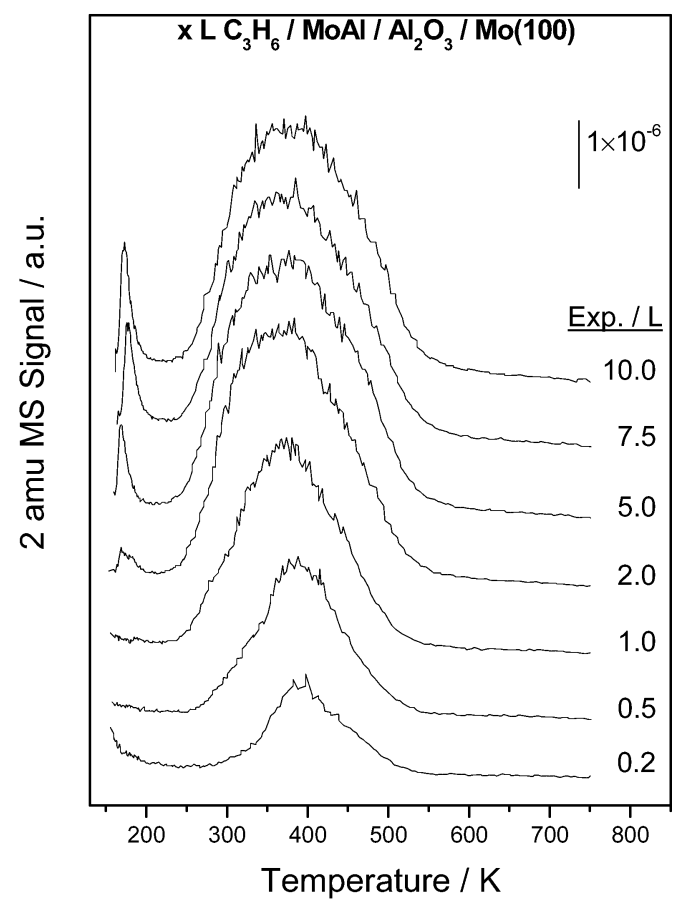

(d)

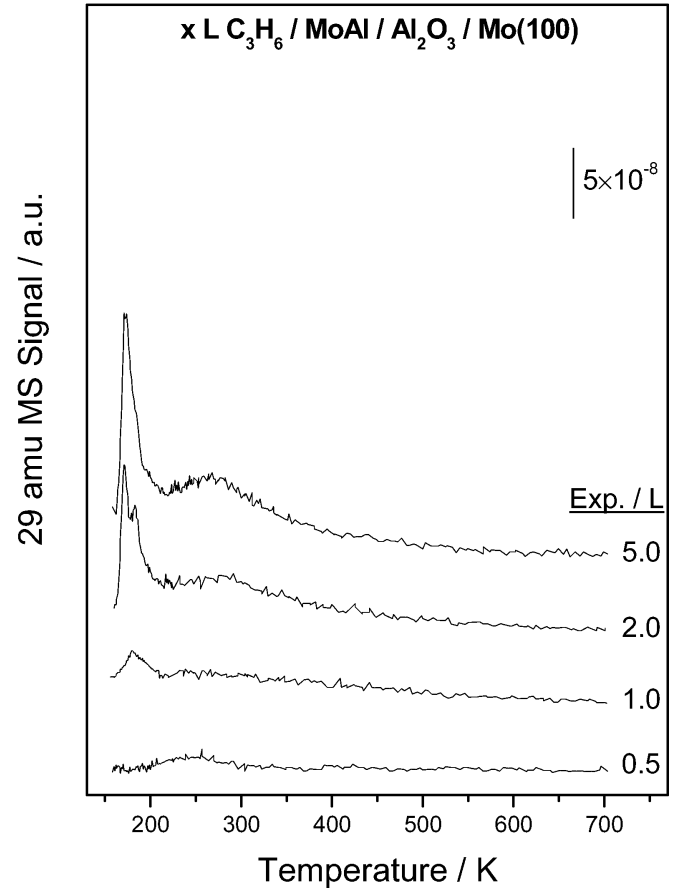

Figure 1. Temperature-programmed desorption spectra of propylene adsorbed on a MoAl alloy at $150 \mathrm{~K}$ as a function of propylene exposure, where the exposures are marked adjacent to the corresponding spectrum, monitoring (a) 42 (propylene), (b) 2 (hydrogen), (c) 16 (methane), and (d) 29 (propane) amu. The data were collected at a heating rate of $10 \mathrm{deg} / \mathrm{s}$.

no propylidyne formation on the surface. The RAIRS results, together with TPD data shown in Figure 1a, suggest that both $\pi$ - and di- $\sigma$-bonded propylene adsorb on the alloy surface and that the former desorbs below $200 \mathrm{~K}$. Efforts were also made to adsorb lower exposures of propylene on the alloy surface at $80 \mathrm{~K}$ to explore whether di- $\sigma$-bonded propylene forms prior to $\pi$-bonded propylene, as seen on other surfaces, ${ }^{30,31}$ but no signal above the noise level could be identified. In fact, even when $10 \mathrm{~L}$ of propylene was adsorbed at $80 \mathrm{~K}$ where relatively strong features can be detected, the quality of the infrared data is substantially worse than that obtained following propylene adsorption on a $\operatorname{Pd}(111)$ single crystal $^{30}$ with use of identical experimental apparatus.

Data shown in Figure 1d indicate that di- $\sigma$-bonded propylene hydrogenates to form propane where surface hydrogen originates from both propylene dissociation (self-hydrogenation) and background $\mathrm{H}_{2}$ adsorption. Since background $\mathrm{H}_{2}$ always adsorbs on the surface during sample cooling, and since it is relatively difficult to choose the proper mass to monitor propane formation (29 and 43 amu contain a contribution from molecular propylene, at least at large propylene exposures, and 44 amu contains a contribution from background $\mathrm{CO}_{2}$ adsorption), propylene self- 


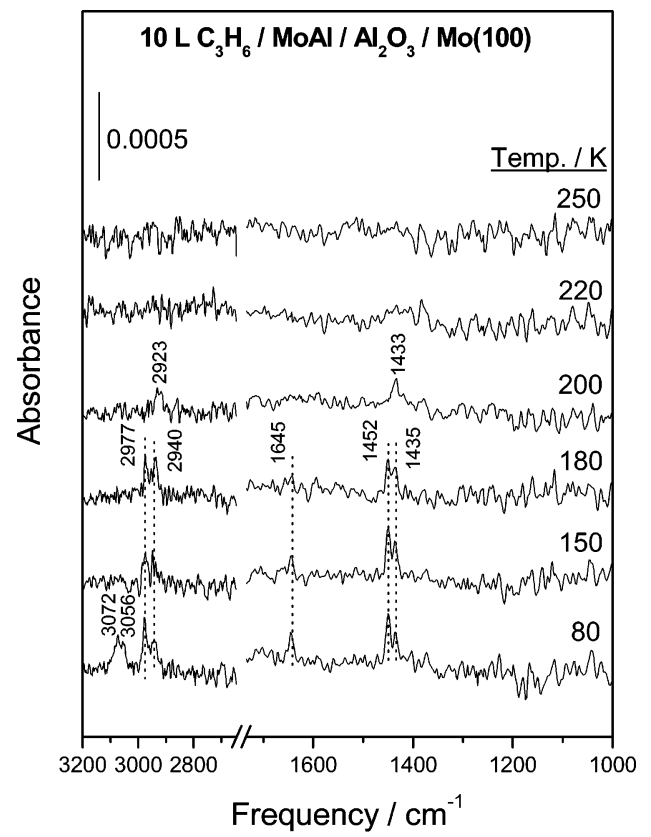

Figure 2. Reflection-absorption infrared spectra (RAIRS) following the adsorption of $10 \mathrm{~L}$ of propylene on a MoAl alloy as a function of annealing temperature, where the annealing temperatures are displayed adjacent to the corresponding spectrum.

TABLE 1: Comparison of the Vibrational Frequencies $\left(\mathrm{cm}^{-1}\right)$ of Propylene Adsorbed on a MoAl Alloy at $80 \mathrm{~K}$ with the Vibrational Frequencies of Solid or Gas-Phase Propylene

\begin{tabular}{clc}
\hline $\begin{array}{c}10 \mathrm{~L} \mathrm{C}_{3} \mathrm{H}_{6} / \\
\text { MoAl at } 80 \mathrm{~K}^{a}\end{array}$ & $\begin{array}{c}\text { solid/gas-phase } \\
\text { propylene }^{b}\end{array}$ & assignment $^{c}$ \\
\hline 3072 & $-/ 3081$ & $v_{\mathrm{a}}\left(\mathrm{CH}_{2}\right)$ \\
3056 & $3064 / 3067$ & overtone \\
2977 & $2970 / 2979$ & $v_{\mathrm{s}}\left(\mathrm{CH}_{2}\right)$ \\
& $-/ 2960$ & $v_{\mathrm{a}}\left(\mathrm{CH}_{3}\right)$ \\
2940 & $2934 / 2942$ & overtone \\
1646 & $1647 / 1647$ & $v(\mathrm{C}=\mathrm{C})$ \\
1452 & $1453 / 1448$ & $\delta_{\mathrm{a}}\left(\mathrm{CH}_{3}\right)$ \\
1435 & $1437 / 1416$ & $\delta\left(\mathrm{CH}_{2}\right)$
\end{tabular}

${ }^{a}$ This work. ${ }^{b}$ Taken from refs 26 and 27. ${ }^{c} v$, stretching; $\delta$, deformation; a, asymmetric; s, symmetric.

hydrogenation and hydrogenation was explored by using $\mathrm{C}_{3} \mathrm{D}_{6}$ and $\mathrm{D}_{2}$ and the results are displayed in Figure 3, where desorption at $52 \mathrm{amu}\left(\mathrm{C}_{3} \mathrm{D}_{8}\right)$ was monitored. Figure 3a depicts propane formation through self-hydrogenation. Almost no $\mathrm{C}_{3} \mathrm{D}_{8}$ desorption is found at a $\mathrm{C}_{3} \mathrm{D}_{6}$ exposure of $0.5 \mathrm{~L}$, while at exposures of $1 \mathrm{~L}$ and above, $\mathrm{C}_{3} \mathrm{D}_{8}$ desorbs at $\sim 260 \mathrm{~K}$, a temperature similar to that seen in Figure 1d. When the alloy surface is predosed with $20 \mathrm{~L}$ of $\mathrm{D}_{2}$ prior to $\mathrm{C}_{3} \mathrm{D}_{6}$ adsorption, the $\mathrm{C}_{3} \mathrm{D}_{8}$ yield is much larger (Figure $3 b$ ). Note that even at a propylene exposure of $0.5 \mathrm{~L}$, where no propane desorption is found from the bare alloy surface, extensive propane desorption occurs from the deuterium-covered surface, at $\sim 260 \mathrm{~K}$. The relative yields of propane (measured by integrating the desorption peak areas) are plotted as an inset to Figure $3 \mathrm{~b}$ as a function of propylene exposure to both bare and deuterium-covered surfaces. In both cases, the propane yield saturates at a propylene exposure of 4 $\mathrm{L}$, while the saturation yield of propane on the deuteriumcovered surface is $\sim 3$ times larger than that on the bare surface. Note also that no propane formation is found below $200 \mathrm{~K}$.

$\mathrm{H}-\mathrm{D}$ exchange reactions were conducted on the alloy surface with TPD to monitor the desorption of propylene and propane isotopomers. Figure $4 \mathrm{a}$ displays the desorption profiles between 29 and 32 amu following a $10 \mathrm{~L} \mathrm{C}_{3} \mathrm{H}_{6}$ exposure to a surface precovered by $20 \mathrm{~L}$ of $\mathrm{D}_{2}$ where these masses are due mainly to $\mathrm{C}_{2}$ fragments of propane isotopomers. Note that the low-
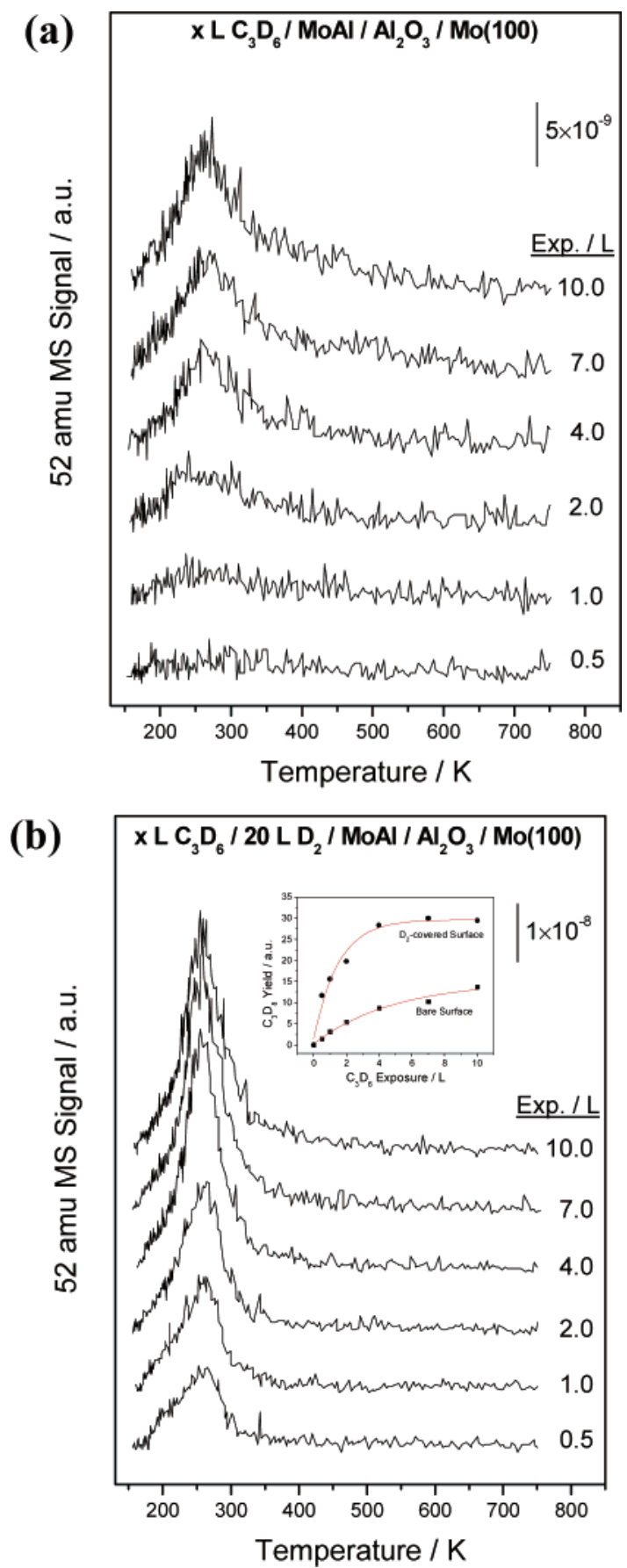

Figure 3. Temperature-programmed desorption spectra of $\mathrm{C}_{3} \mathrm{D}_{6}$ adsorbed on (a) a clean MoAl alloy surface and (b) an alloy surface precovered by $20 \mathrm{~L}$ of $\mathrm{D}_{2}$, monitoring $52 \mathrm{amu}$ (propane) as a function of $\mathrm{C}_{3} \mathrm{D}_{6}$ exposure, where the exposures are marked adjacent to the corresponding spectrum. Shown as an inset is a plot of the propane yield as a function of propylene exposure on the clean and deuteriumcovered alloy surface.

temperature desorption at 29 and $30 \mathrm{amu}$ is due to fragmentation of molecular $\mathrm{C}_{3} \mathrm{H}_{6}$ (Figure 1d). These desorption profiles clearly indicate that $\mathrm{H}-\mathrm{D}$ exchange does occur on the surface and that the propane isotopomers desorb at $\sim 260 \mathrm{~K}$, indicating that only di- $\sigma$-bonded propylene undergoes $\mathrm{H}-\mathrm{D}$ exchanges, as suggested previously. ${ }^{32}$ Figure $4 \mathrm{~b}$ displays the corresponding spectra between 43 and 52 amu. Masses above 48 amu can be assigned unambiguously to propane isotopomers; in particular the 51 and 52 amu signals are assigned to $\mathrm{C}_{3} \mathrm{HD}_{7}$ and $\mathrm{C}_{3} \mathrm{D}_{8}$, respectively. However, the desorption profiles at from 43 to 48 amu may contain contributions from both propylene and propane isoto- 

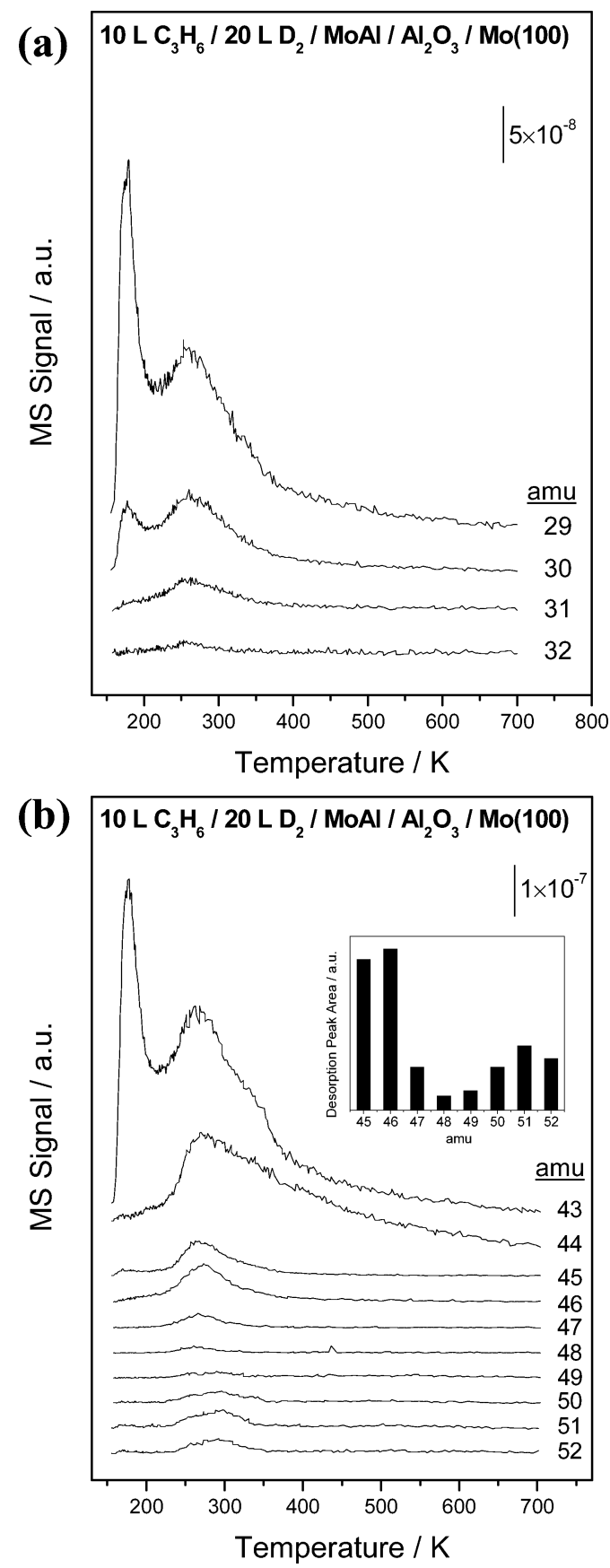

Figure 4. Temperature-programmed desorption spectra of $10 \mathrm{~L}$ of $\mathrm{C}_{3} \mathrm{H}_{6}$ adsorbed on an alloy surface precovered by $20 \mathrm{~L}$ of $\mathrm{D}_{2}$, monitoring (a) 29 to $32 \mathrm{amu}$ and (b) 43 to $52 \mathrm{amu}$. Shown as an inset is a plot of the desorption yield as a function of mass.

pomers and this will be discussed in more detail below. Note that the low-temperature peak at $43 \mathrm{amu}$ is due to propylene, and the high-temperature tail of the 44 amu signal is due to some background $\mathrm{CO}_{2}$ adsorption. More interestingly, the relative yields of these masses (measured from the integrated areas under the desorption peaks) display a U-shape distribution as shown in the inset to Figure 4b. Experiments were also performed by varying the propylene and $\mathrm{D}_{2}$ exposures (data not shown). Although the relative yields of different masses vary slightly in different cases, the U-shape distribution is always maintained as long as the $\mathrm{D}_{2}$ exposure is greater than the propylene exposure. Note also that the desorption temperature of the 49 to $52 \mathrm{amu}$ features is also slightly higher than that for the 43 to 48 amu signals.

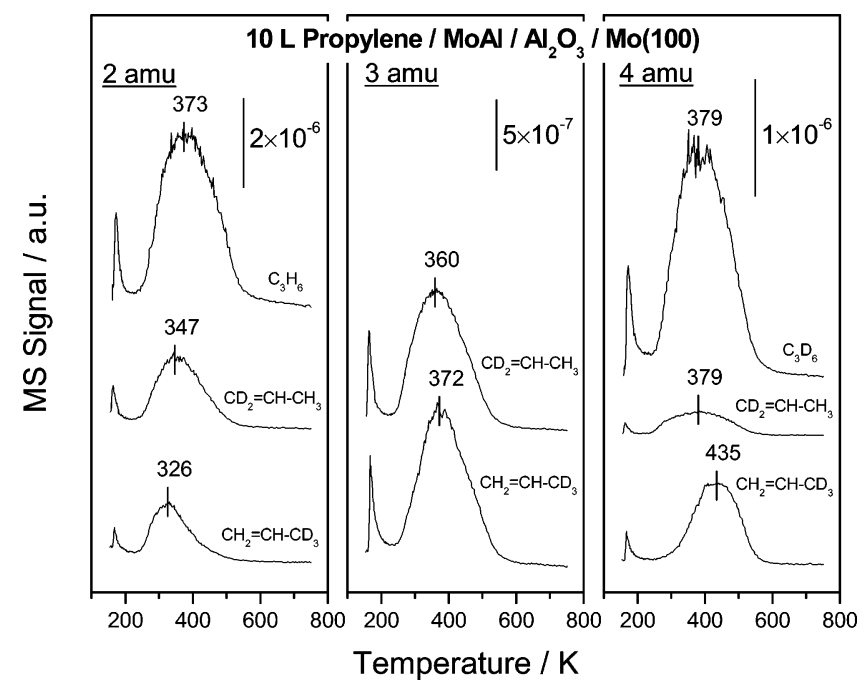

Figure 5. Temperature-programmed desorption spectra of $10 \mathrm{~L}$ of various propylene isotopomers on a MoAl alloy: $\mathrm{C}_{3} \mathrm{D}_{6}, \mathrm{CH}_{2}=\mathrm{CH}-$ $\mathrm{CD}_{3}$, and $\mathrm{CD}_{2}=\mathrm{CH}-\mathrm{CH}_{3}$ monitoring the desorption of $2\left(\mathrm{H}_{2}\right), 3(\mathrm{HD})$, and $4\left(\mathrm{D}_{2}\right)$ amu.

Carbon deposition was detected by using Auger spectroscopy following propylene adsorption when the sample was heated to above $750 \mathrm{~K}$. The deposited carbon (as a carbide) is easily removed by annealing the sample to above $1200 \mathrm{~K}$, where it reacts with the alumina substrate to form $\mathrm{CO}$. This has been described in detail recently for an analogous situation for ethylene. $^{22}$

The data shown in Figure 2 reveal that no detectable infrared features persist on the surface after annealing the alloy above $220 \mathrm{~K}$, nor following propylene exposure to the alloy surface at room temperature. However, TPD experiments detect methane formation (Figure 1c), although with rather low yields. This indicates that some surface $\mathrm{C}_{1}$ species are generated during propylene decomposition. To gain a better understanding of the dissociation process, TPD experiments were performed with deuterium-labeled propylene including $\mathrm{CD}_{2}=\mathrm{CH}-\mathrm{CH}_{3}$ and $\mathrm{CH}_{2}=\mathrm{CH}-\mathrm{CD}_{3}$ to monitor desorption of $\mathrm{H}_{2}, \mathrm{HD}$, and $\mathrm{D}_{2}$. Note first that adsorbing $\mathrm{H}_{2}$ and $\mathrm{D}_{2}$ on the alloy surface results in recombinative desorption at $\sim 300 \mathrm{~K}$ at high exposures. Since background $\mathrm{H}_{2}$ always adsorbs on the surface, this will inevitably affect the desorption temperature of $\mathrm{H}_{2}$ and $\mathrm{HD}$; a $10 \mathrm{~L}$ exposure of propylenes was used to eliminate this effect.

As seen in Figure 5, by adsorbing $10 \mathrm{~L}$ of $\mathrm{C}_{3} \mathrm{H}_{6}$ on the surface, $\mathrm{H}_{2}$ desorbs at a $T_{\max }$ of $373 \mathrm{~K}$. This is essentially identical with the deuterium desorption temperature following adsorption of $10 \mathrm{~L}$ of $\mathrm{C}_{3} \mathrm{D}_{6}$. This rules out any large kinetic isotope effect on the desorption temperature. Following the adsorption of $10 \mathrm{~L}$ of $\mathrm{CD}_{2}=\mathrm{CH}-\mathrm{CH}_{3}, \mathrm{H}_{2}$ desorbs at $347 \mathrm{~K}$, $\mathrm{HD}$ desorbs at $360 \mathrm{~K}$, while $\mathrm{D}_{2}$ desorbs at $379 \mathrm{~K}$. In stark contrast, the desorption temperatures of $\mathrm{H}_{2}, \mathrm{HD}$, and $\mathrm{D}_{2}$ are 326,372 , and $435 \mathrm{~K}$, respectively, following the dissociation of $\mathrm{CH}_{2}=\mathrm{CH}-\mathrm{CD}_{3}$. These results provide some insights in the dissociation of propylene and will be discussed in more detail below. Note finally that no ethylene formation has been detected by comparing the relative intensities of various masses during propylene desorption.

3.2. 1-Iodopropane on a MoAl Alloy. Figure 6 displays RAIRS data collected following the adsorption of various exposures of 1-iodopropane to the alloy surface and subsequently annealing to higher temperatures where the exposures and annealing temperatures are marked adjacent to the corresponding spectrum. Adsorbing $1 \mathrm{~L}$ of 1-iodopropane at $80 \mathrm{~K}$ 


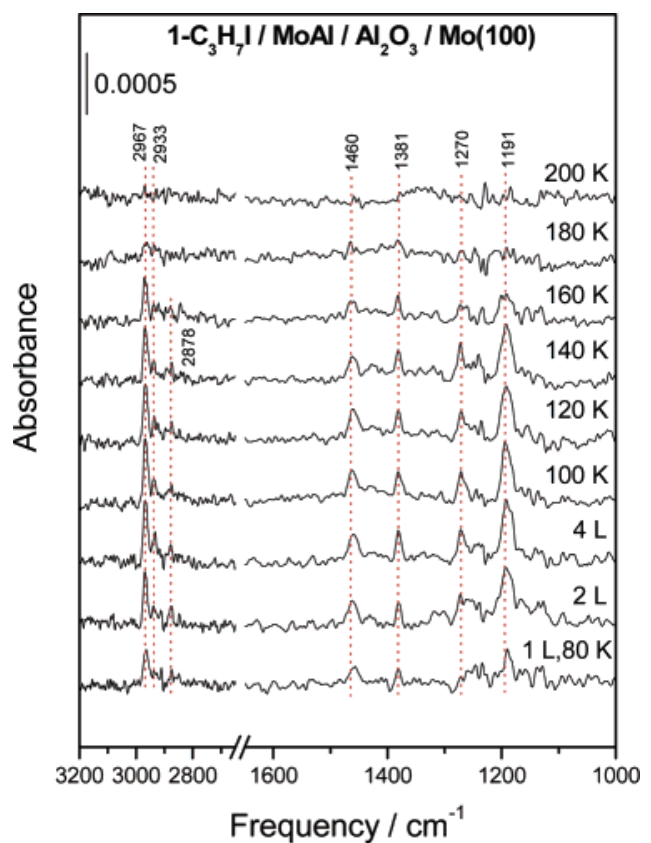

Figure 6. Reflection-absorption infrared spectra (RAIRS) following the adsorption of 1-iodopropane on a MoAl alloy as a function of exposure and annealing temperature, where the exposures and annealing temperatures are displayed adjacent to the corresponding spectrum.

TABLE 2: Comparison of the Vibrational Frequencies $\left(\mathrm{cm}^{-1}\right)$ of 1-Iodopropane Adsorbed on a MoAl Alloy at $80 \mathrm{~K}$ with the Vibrational Frequencies of Liquid 1-Iodopropane

\begin{tabular}{lll}
\hline $\begin{array}{c}\text { liquid } \\
\text { 1-iodopropane }\end{array}$ & $\begin{array}{c}\text { 4 L 1-iodopropane/ } \\
\text { MoAl at } 80 \mathrm{~K}^{b}\end{array}$ & \multicolumn{1}{c}{ assignment $^{c}$} \\
\hline 2967 & 2967 & $\nu_{\mathrm{a}}\left(\mathrm{CH}_{3}\right)$ \\
2846,2938 & 2933 & $\nu\left(\mathrm{CH}_{2}\right)$ \\
2876 & 2878 & $v_{\mathrm{s}}\left(\mathrm{CH}_{3}\right)$ \\
1458 & 1460 & $\delta_{\mathrm{a}}\left(\mathrm{CH}_{3}\right)$ \\
1435 & & $\gamma_{\mathrm{s}}\left(\mathrm{CH}_{2}\right)$ \\
1380 & 1381 & $\delta_{\mathrm{s}}\left(\mathrm{CH}_{3}\right)$ \\
& 1270 & $v(\mathrm{CC})+\delta\left(\mathrm{CCC}^{2}\right)$ \\
1185 & 1191,1183 & $\tau(\mathrm{CH})_{\beta}, \omega\left(\mathrm{CH}_{2}\right)_{\alpha}$ \\
1090 & & $v(\mathrm{CC})$ or $\rho\left(\mathrm{CH}_{3}\right)$
\end{tabular}

${ }^{a}$ Taken from refs $33-35{ }^{b}$ This work. ${ }^{c} v$, stretching; $\delta$, deformation; $\gamma$, scissoring; $\tau$, twisting; $\omega$, wagging; $\rho$, rocking; a, asymmetric; $\mathrm{s}$, symmetric; $\alpha$, methylene bonded to iodine; $\beta$, methylene bonded to methyl.

results in the appearance of infrared modes assignable to molecular 1-iodopropane, ${ }^{33-35}$ suggesting molecular adsorption (see Table 2). Note that the mode at $1270 \mathrm{~cm}^{-1}$ assigned to $v(\mathrm{CC})+\delta(\mathrm{CCC})$ is absent, indicating that the molecules lie rather flat on the surface. This mode becomes clear at exposures of 2 and $4 \mathrm{~L}$, accompanied by an intensity increase of the other features. Annealing to $140 \mathrm{~K}$ does not result in any detectable change in infrared features but the intensities decrease on heating to $160 \mathrm{~K}$, indicating molecular desorption. By $180 \mathrm{~K}$, a further intensity decrease is found, while molecular modes are still detectable. By $200 \mathrm{~K}$, all modes belonging to molecular $1-\mathrm{C}_{3} \mathrm{H}_{7} \mathrm{I}$ disappear and no strong features due to propyl or propyl-derived species could be detected.

Figure 7 a displays the narrow XPS scan data of the I $3 d_{5 / 2}$ region following the adsorption of $10 \mathrm{~L}$ of $1-\mathrm{C}_{3} \mathrm{H}_{7} \mathrm{I}$ on the alloy surface at $150 \mathrm{~K}$ and subsequently annealing to higher temperatures. An I $3 d_{5 / 2}$ binding energy is found at $620.2 \mathrm{eV}$ at 150 $\mathrm{K}$. Annealing to $160 \mathrm{~K}$ caused the signal intensity to decrease slightly and the binding energy is shifted to $620.0 \mathrm{eV}$. Upon heating the sample to $180 \mathrm{~K}$, a further signal intensity decrease was found and the binding energy shifted to $619.8 \mathrm{eV}$. Drastic
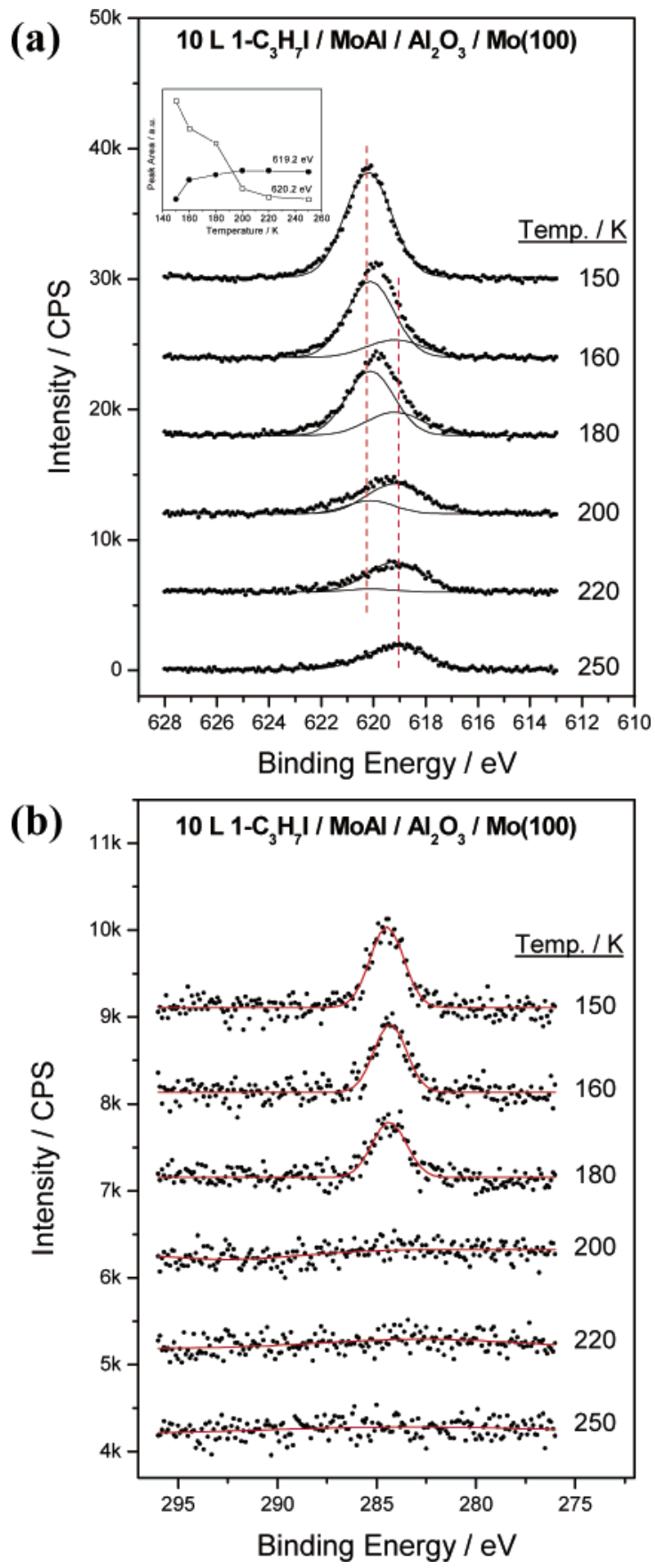

Figure 7. (a) $\mathrm{I} 3 \mathrm{~d}_{5 / 2}$ and (b) $\mathrm{C} 1 \mathrm{~s}$ photoelectron spectra of $10 \mathrm{~L}$ of 1 -iodopropane adsorbed on a MoAl surface at $150 \mathrm{~K}$ and heated to various temperatures, where the annealing temperatures are displayed adjacent to the corresponding spectrum. Shown as an inset are the areas of the I $3 \mathrm{~d}_{5 / 2}$ signals from 1-iodopropane (centered at $620.2 \mathrm{eV}$ ) and atomic iodine (centered at $619.2 \mathrm{eV}$ ) plotted as a function of temperature.

change occurs at $200 \mathrm{~K}$. Besides a substantial decrease in signal intensity, the binding energy also decreases substantially to $619.45 \mathrm{eV}$. This suggests that, together with desorption of molecular $1-\mathrm{C}_{3} \mathrm{H}_{7} \mathrm{I}$, extensive $\mathrm{C}-\mathrm{I}$ bond cleavage occurs. An I $3 \mathrm{~d}_{5 / 2}$ binding energy of $619.2 \mathrm{eV}$ was found after the sample had been heated to 220 and $250 \mathrm{~K}$ and, in the meantime, no further signal intensity decrease was observed. On the basis of RAIRS data shown in Figure 6 and TPD results presented below, the $\sim 620.2 \mathrm{eV} \mathrm{I} 3 \mathrm{~d}_{5 / 2}$ signal feature is due to iodine in molecular $\mathrm{C}_{3} \mathrm{H}_{7} \mathrm{I}$, while the feature at $619.2 \mathrm{eV}$ represents adsorbed iodine formed by $\mathrm{C}-\mathrm{I}$ bond cleavage. All features were therefore fitted into two Gaussian curves centered at 620.2 and $619.2 \mathrm{eV}$, 

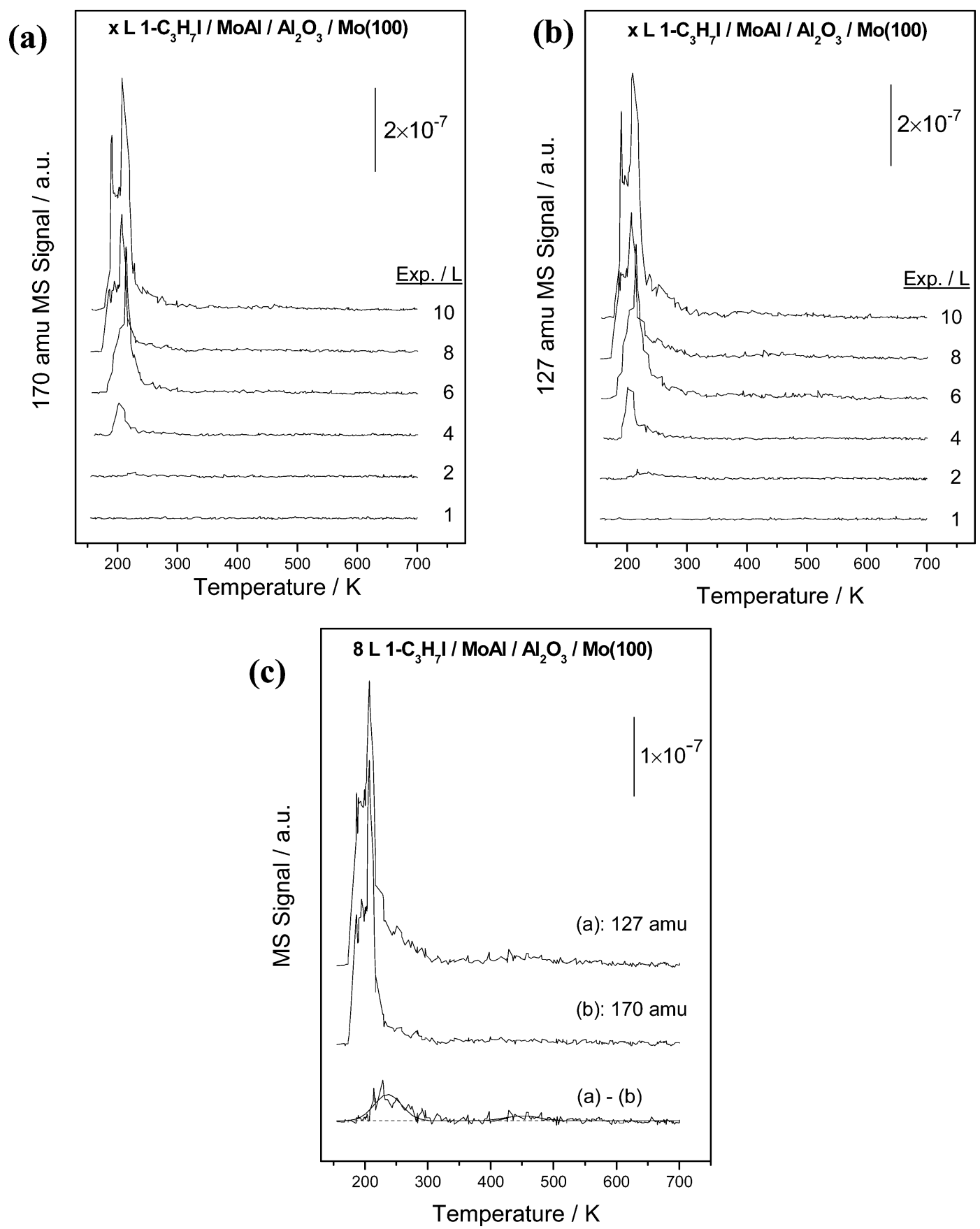

Figure 8. Temperature-programmed desorption spectra of 1-iodopropnae adsorbed on a MoAl alloy at $150 \mathrm{~K}$ as a function of 1-iodopropane exposure, where the exposures are marked adjacent to the corresponding spectrum, monitoring (a) 170 (1-iodopropane) and (b) 127 (iodine) amu. The data were collected at a heating rate of $10 \mathrm{deg} / \mathrm{s}$. Shown in panel $\mathrm{c}$ is the difference between the 127 and $170 \mathrm{amu}$ spectra.

respectively, each curve having a fwhm of $\leq 2 \mathrm{eV}$, where only the amplitude and background were allowed to vary. The area under each curve is also plotted versus annealing temperature, as an inset to Figure 7a. This clearly demonstrates that molecular desorption ceases at $\sim 220 \mathrm{~K}$ and $\mathrm{C}-\mathrm{I}$ bond cleavage commences as low as $160 \mathrm{~K}$ and by $200 \mathrm{~K}$ it is almost complete. Figure $7 \mathrm{~b}$ displays the corresponding $\mathrm{C} 1 \mathrm{~s}$ spectra where a $\mathrm{C}$ 1s binding energy was found at $284.5 \mathrm{eV}$ at $150 \mathrm{~K}$, which decreased slightly to $284.4 \mathrm{eV}$ at $160 \mathrm{~K}$ and $284.35 \mathrm{eV}$ at 180 $\mathrm{K}$, together with a slight intensity decrease as the sample was heated. Again, in accord with Figure 7a, the signal intensity decreases substantially at $200 \mathrm{~K}$ suggesting extensive molecular desorption. Due to low signal intensity, no efforts were made to fit these curves into different components.
The surface chemistry of $1-\mathrm{C}_{3} \mathrm{H}_{7} \mathrm{I}$ on the alloy surface was further investigated with TPD. Figure 8a displays the desorption profile of the parent molecule (at $170 \mathrm{amu}$ ). No molecular desorption is found at an exposure of $1 \mathrm{~L}$, suggesting complete 1- $\mathrm{C}_{3} \mathrm{H}_{7} \mathrm{I}$ dissociation. At an exposure of $2 \mathrm{~L}$, very weak desorption is found at $\sim 220 \mathrm{~K}$. The temperature of this state decreases to $\sim 210 \mathrm{~K}$ with increasing $1-\mathrm{C}_{3} \mathrm{H}_{7} \mathrm{I}$ exposure, while the desorption yield continues to increase. At the highest exposure $(10 \mathrm{~L})$, a sharp feature appears at $\sim 190 \mathrm{~K}$, assigned to multilayer desorption, while the $210-220 \mathrm{~K}$ state is attributed to $1-\mathrm{C}_{3} \mathrm{H}_{7} \mathrm{I}$ desorption from the monolayer. Figure $7 \mathrm{~b}$ depicts the corresponding $127 \mathrm{amu}\left(\mathrm{I}^{+}\right)$desorption features. These are very similar to those at 170 amu suggesting that they are due mainly to molecular fragmentation. However, there are subtle 

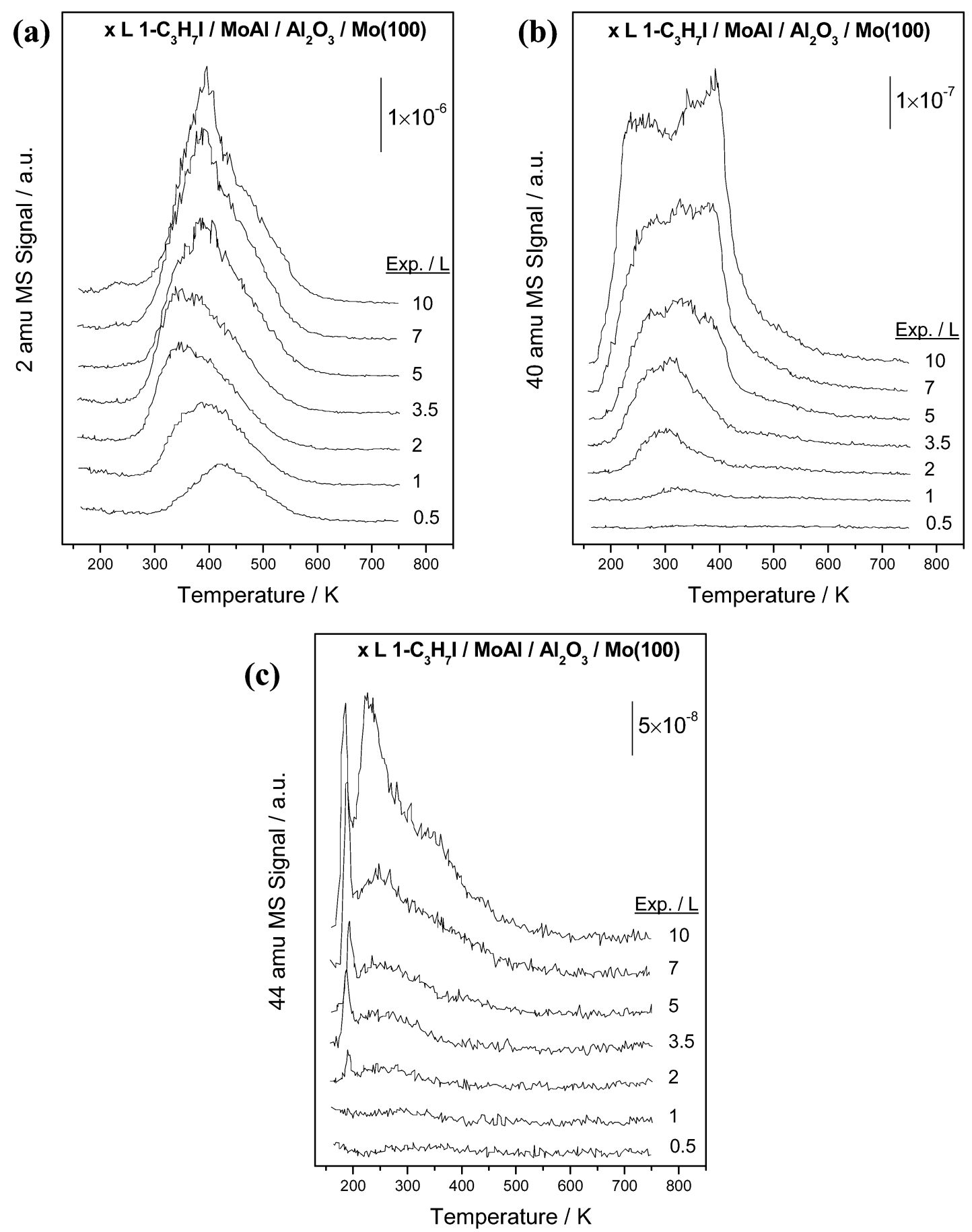

Figure 9. Temperature-programmed desorption spectra of 1-iodopropane adsorbed on a MoAl alloy at $150 \mathrm{~K}$ as a function of propylene exposure, where the exposures are marked adjacent to the corresponding spectrum, monitoring (a) 2 (hydrogen), (b) 40 (propylene), and (c) 44 (propane) amu. The data were collected at a heating rate of $10 \mathrm{deg} / \mathrm{s}$.

differences. First, some extra desorption is found to high temperatures of the molecular desorption peak (at $\sim 250 \mathrm{~K}$ ). Second, weak yet detectable intensity appears at $\sim 400 \mathrm{~K}$, especially at high $1-\mathrm{C}_{3} \mathrm{H}_{7} \mathrm{I}$ exposures. This is highlighted in Figure $7 \mathrm{c}$ by performing a simple subtraction of the 127 and 170 amu signals at an $1-\mathrm{C}_{3} \mathrm{H}_{7} \mathrm{I}$ exposure of $8 \mathrm{~L}$. The $\sim 250 \mathrm{~K}$ feature is tentatively assigned to $\mathrm{HI}$ desorption and the $\sim 400$ $\mathrm{K}$ feature to iodine-containing organoaluminum compounds (even though the chemical stoichiometry cannot be determined).

Figure 9 plots the desorption of reaction products from adsorbed $1-\mathrm{C}_{3} \mathrm{H}_{7} \mathrm{I}$. Figure 9 a displays the $\mathrm{H}_{2}$ desorption profiles as a function of $1-\mathrm{C}_{3} \mathrm{H}_{7} \mathrm{I}$ exposure. At the lowest iodopropane exposure $(0.5 \mathrm{~L}), \mathrm{H}_{2}$ desorbs at $\sim 410 \mathrm{~K}$, while between 1 and $3.5 \mathrm{~L}$, the $\mathrm{H}_{2}$ yield increases and the desorption temperature decreases. Note especially that at exposures of 2 and $3.5 \mathrm{~L}, \mathrm{H}_{2}$ desorbs at $\sim 350 \mathrm{~K}$. The $\mathrm{H}_{2}$ yield saturates at $1-\mathrm{C}_{3} \mathrm{H}_{7} \mathrm{I}$ exposures of $7.5 \mathrm{~L}$ and higher, and the peak temperature increases to $\sim 380$ K. Figure $9 \mathrm{~b}$ depicts the $40 \mathrm{amu}$ (propylene) desorption profiles where this mass is selected because it contains the lowest contribution from the parent molecule and thus more accurately represents propylene, even though the signal intensity is substantially lower than at 41 or 42 amu. At a $1-\mathrm{C}_{3} \mathrm{H}_{7} \mathrm{I}$ exposure of $0.5 \mathrm{~L}$, essentially no propylene desorption is found, while a weak feature centered at $\sim 310 \mathrm{~K}$ is detected at an exposure of 1 L. The desorption temperature decreases to $\sim 300 \mathrm{~K}$ at exposures of 2 and $3.5 \mathrm{~L}$. At higher exposures, besides the intensity increase of this desorption state, another high-temperature state starts to develop at $\sim 380 \mathrm{~K}$. The low-temperature 

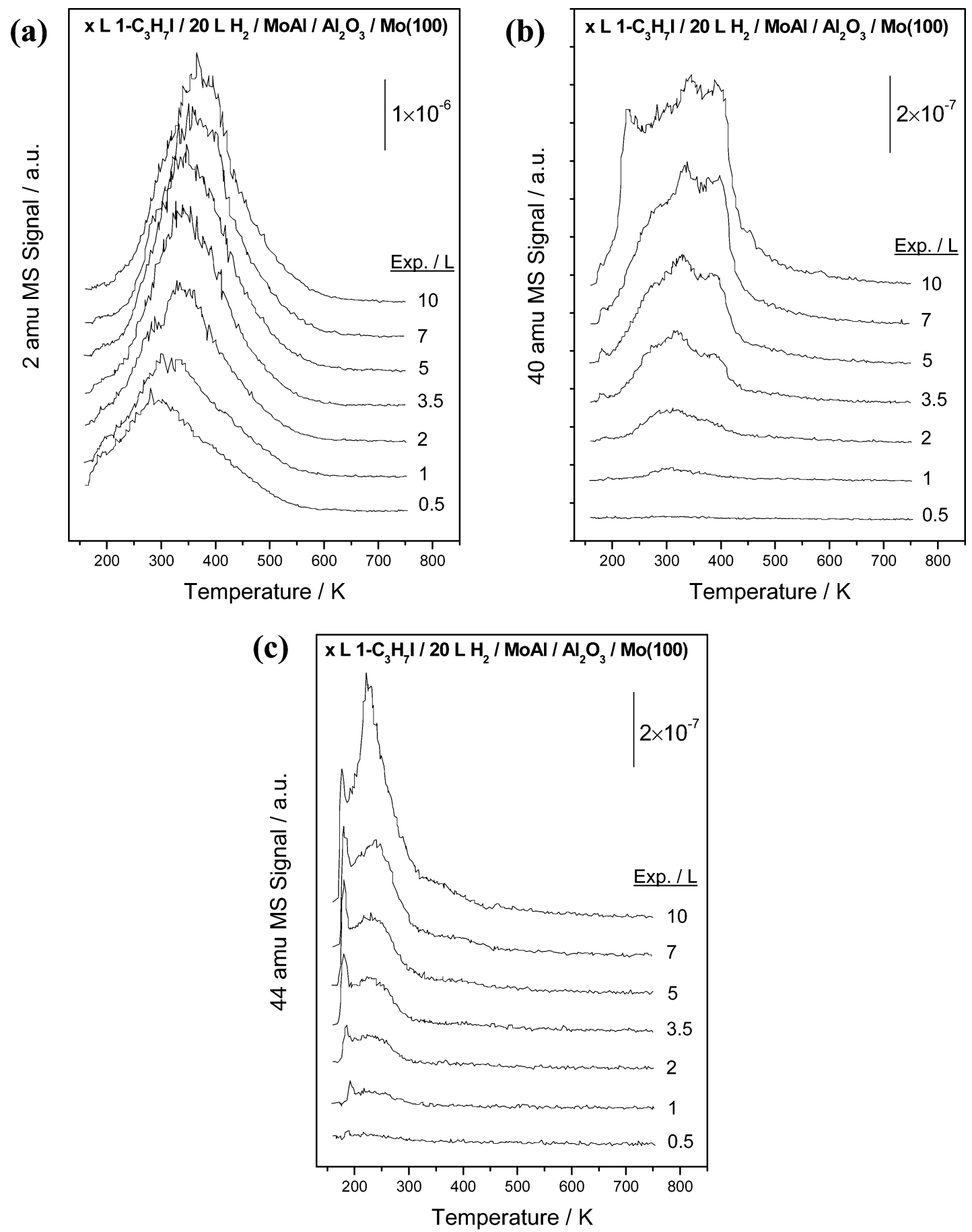

Figure 10. Temperature-programmed desorption spectra of various exposures of 1-iodopropane adsorbed on an alloy surface precovered by $20 \mathrm{~L}$ of $\mathrm{H}_{2}$, monitoring (a) 2 (hydrogen), (b) 40 (propylene), and (c) 44 (propane) amu. The 1-iodopropane exposures are marked adjacent to the corresponding spectrum.

shoulder appearing at high 1-iodopropane exposures is due to fragmentation of the parent molecule. Figure 9c plots the corresponding 44 amu (propane) desorption profiles. Only very weak propane desorption is found at $1-\mathrm{C}_{3} \mathrm{H}_{7} \mathrm{I}$ exposures of 0.5 and $1 \mathrm{~L}$ so that the desorption temperature cannot be accurately determined. At higher $1-\mathrm{C}_{3} \mathrm{H}_{7} \mathrm{I}$ exposures, two propane desorption states are found: a sharp, low-temperature state at $\sim 190$ $\mathrm{K}$ independent of $1-\mathrm{C}_{3} \mathrm{H}_{7} \mathrm{I}$ exposure and a broad, hightemperature state between 265 and $240 \mathrm{~K}$, with a desorption temperature decreasing with increasing $1-\mathrm{C}_{3} \mathrm{H}_{7} \mathrm{I}$ exposure. At the highest $1-\mathrm{C}_{3} \mathrm{H}_{7} \mathrm{I}$ exposure $(10 \mathrm{~L})$, these two states contain some contribution from fragmentation of the parent molecule. Note, however, another high-temperature propane desorption state develops at $\sim 340 \mathrm{~K}$ at the highest 1-iodopropane exposure. A number of other masses were also monitored and no other molecules, for instance oxygenates or methane, were observed. Following the dissociation of $1-\mathrm{C}_{3} \mathrm{H}_{7} \mathrm{I}$ on the alloy surface, atomic carbon and iodine are deposited. These desorb at high temperatures in the form of $\mathrm{CO}$ and atomic iodine, respectively. Analogous behavior has been reported previously following the dissociation of $\mathrm{CH}_{3} \mathrm{I}, \mathrm{CH}_{2} \mathrm{I}_{2}$, and $\mathrm{C}_{2} \mathrm{H}_{5} \mathrm{I}$ on the same surface, ${ }^{20-22}$ and will therefore not be discussed further.

Figure 10 displays a similar series of TPD profiles on an alloy surface initially exposed to $20 \mathrm{~L}$ of $\mathrm{H}_{2}$, to further investigate the hydrogenation of $1-\mathrm{C}_{3} \mathrm{H}_{7} \mathrm{I}$. Figure 10a plots the $2 \mathrm{amu}\left(\mathrm{H}_{2}\right)$ desorption profiles. At the lowest $1-\mathrm{C}_{3} \mathrm{H}_{7} \mathrm{I}$ exposure, 


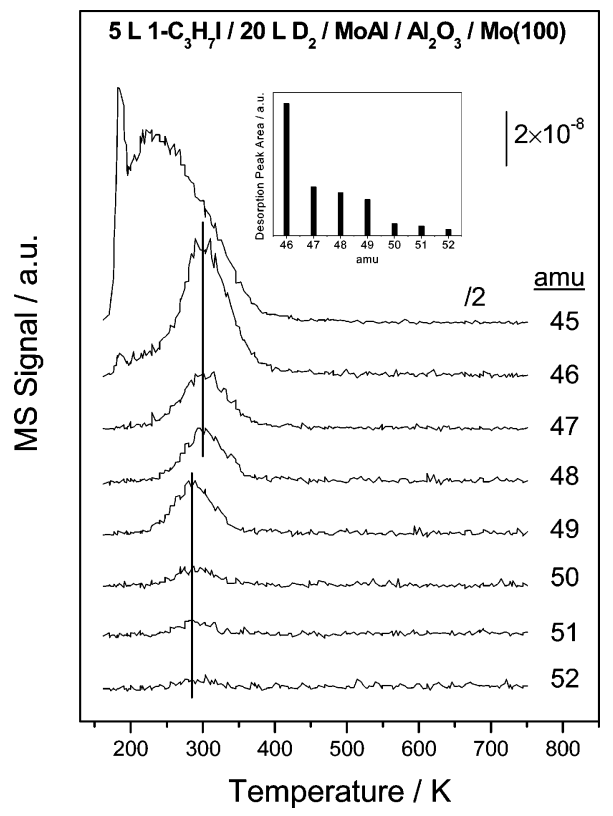

Figure 11. Temperature-programmed desorption spectra of $5 \mathrm{~L}$ of $1-\mathrm{C}_{3} \mathrm{H}_{7} \mathrm{I}$ adsorbed on an alloy surface precovered by $20 \mathrm{~L}$ of $\mathrm{D}_{2}$, monitoring 45 to $52 \mathrm{amu}$. Shown as an inset is a plot of the desorption yield as a function of mass.

$\mathrm{H}_{2}$ desorbs at $\sim 286 \mathrm{~K}$ where the desorption temperature increases monotonically with increasing $1-\mathrm{C}_{3} \mathrm{H}_{7} \mathrm{I}$ exposure, so that at the highest exposure $(10 \mathrm{~L})$, it reaches $\sim 370 \mathrm{~K}$. This behavior is different from that shown in Figure 9a and will be discussed in more detail below. The propylene desorption profiles shown in Figure 10b appear to be similar to those seen in Figure 9b, except that the $\sim 310 \mathrm{~K}$ state at high $1-\mathrm{C}_{3} \mathrm{H}_{7} \mathrm{I}$ exposures is always more intense than the $\sim 380 \mathrm{~K}$ state, while this is not always true on the bare surface. Figure 10c plots the corresponding 44 amu (propane) desorption profile where it is found that the propane yields are substantially higher on a hydrogen-covered surface (note the different scale for Figures $9 \mathrm{c}$ and 10c). Worthy of note is that, even at the lowest $1-\mathrm{C}_{3} \mathrm{H}_{7} \mathrm{I}$ exposure, propane is detected at $\sim 190 \mathrm{~K}$.

Finally, $\mathrm{H}-\mathrm{D}$ exchange reactions are explored by adsorbing $5 \mathrm{~L}$ of $1-\mathrm{C}_{3} \mathrm{H}_{7} \mathrm{I}$ on an alloy surface precovered with $20 \mathrm{~L}$ of $\mathrm{D}_{2}$ and the results are plotted in Figure 11. Note first that the desorption yield at $45 \mathrm{amu}$ is substantially larger than that at higher masses. The desorption line shape at this mass is rather similar to that seen in Figure 10c suggesting that this is due mainly to $\mathrm{C}_{3} \mathrm{H}_{7} \mathrm{D}$ desorption. In contrast, for masses between 46 and $48 \mathrm{amu}$, a single desorption state is detected at $\sim 300 \mathrm{~K}$ with a desorption yield that decreases at higher masses. For masses between 49 and 52 amu, again a single desorption state is observed with a desorption yield that decreases at higher masses, but the desorption temperature decreases to $\sim 283 \mathrm{~K}$. The relative desorption yields between 46 and 52 amu are plotted as an inset to Figure 11. Again, masses between 49 and $52 \mathrm{amu}$ are readily assigned to propane isotopomers, namely $\mathrm{C}_{3} \mathrm{H}_{3} \mathrm{D}_{5}, \mathrm{C}_{3} \mathrm{H}_{2} \mathrm{D}_{6}, \mathrm{C}_{3} \mathrm{HD}_{7}$, and $\mathrm{C}_{3} \mathrm{D}_{8}$, although higher masses may have fragments contributing to the lower masses. The features from 46 to 48 amu are harder to assign unambiguously since these might contain contributions from both propylene and propane isotopomers. However, the $\sim 17 \mathrm{~K}$ peak temperature difference between these features and those due to the propane isotopomers suggests that these are due mainly to propylene isotopomers, considering the fact that propylene (Figure 10b) desorbs at higher temperatures than propane (Figure 10c).
3.3. 1,3-Diiodopropane (DIP) on a MoAl Alloy. The interaction between 1,3-diiodopropane (DIP) and the MoAl surface was investigated with RAIRS. Figure 12a displays the RAIRS spectra obtained following exposure of the alloy to 10 $\mathrm{L}$ of DIP at $80 \mathrm{~K}$, where weak features are detected in the $\mathrm{C}-\mathrm{H}$ stretching region at 2955,2882 , and $2832 \mathrm{~cm}^{-1}$. At lower frequencies, strong features are found at 1414, 1343, and 1275 $\mathrm{cm}^{-1}$, where the most intense feature is at $1197 \mathrm{~cm}^{-1}$. Annealing to $170 \mathrm{~K}$ causes the intensities in the $\mathrm{C}-\mathrm{H}$ stretching region to decrease drastically, while the features at 1414, 1343, 1275, and $1197 \mathrm{~cm}^{-1}$ attenuate slightly, and drastic changes occur after heating to $200 \mathrm{~K}$. The $2955-\mathrm{cm}^{-1}$ feature shifts to 2947 $\mathrm{cm}^{-1}$ and the signal intensity increases substantially and additional intense features appear at 1302 and $1155 \mathrm{~cm}^{-1}$. The intensity of the $1414-\mathrm{cm}^{-1}$ peak increases and it shifts to 1423 $\mathrm{cm}^{-1}$, and a detectable shoulder appears at $1435 \mathrm{~cm}^{-1}$. The intensities of features at 1343 and $1197 \mathrm{~cm}^{-1}$ also increase, while a decrease is found for the $1275-\mathrm{cm}^{-1}$ mode.

RAIRS spectra were also collected after exposure to $2 \mathrm{~L}$ of DIP (Figure 12b) to more clearly examine the chemistry of DIP adsorbed on the alloy surface. Relatively intense features are found at 1275 and $1199 \mathrm{~cm}^{-1}$ following DIP adsorption at 80 $\mathrm{K}$. No features are detected in the $\mathrm{C}-\mathrm{H}$ stretching region (not shown). These features do not change dramatically upon annealing the sample to $180 \mathrm{~K}$, but at $200 \mathrm{~K}$, the intensity of these peaks decreases substantially. Note that a new feature appears at $\sim 1190 \mathrm{~cm}^{-1}$ at $200 \mathrm{~K}$ (as a shoulder of the 1199 $\mathrm{cm}^{-1}$ signal) and is still detectable at $230 \mathrm{~K}$. No features are detectable by $250 \mathrm{~K}$. DIP was also adsorbed on the alloy surface at room temperature (data not plotted) and no features were detected.

XPS experiments were performed by adsorbing $5 \mathrm{~L}$ of DIP on the alloy surface at $150 \mathrm{~K}$ and subsequently annealing to higher temperatures to determine the $\mathrm{C}-\mathrm{I}$ bond cleavage temperature. Panels a and $\mathrm{b}$ of Figure 13 display the $\mathrm{I} 3 \mathrm{~d}_{5 / 2}$ and $\mathrm{C} 1 \mathrm{~s}$ regions, respectively, which are very similar to those for $1-\mathrm{C}_{3} \mathrm{H}_{7} \mathrm{I}$ shown in Figure 7. The components of the spectra were identified in the same way as shown in Figure $7 \mathrm{a}$ and the inset demonstrates clearly that molecular desorption ceases at $\sim 230$ $\mathrm{K}$ and $\mathrm{C}-\mathrm{I}$ bond cleavage is complete by $\sim 200 \mathrm{~K}$. Note that DIP desorbs at slightly higher temperatures than $1-\mathrm{C}_{3} \mathrm{H}_{7} \mathrm{I}$.

TPD experiments were conducted to determine the surface reaction products from DIP. Figure 14a displays desorption profiles at 169 amu $\left(\mathrm{C}_{3} \mathrm{H}_{6} \mathrm{I}^{+}\right)$, which represents exclusively molecular desorption. Essentially no DIP desorption is found at exposures of 1 and $2 \mathrm{~L}$. At an exposure of $4 \mathrm{~L}$, a sharp desorption state is found at $\sim 210 \mathrm{~K}$ with a high-temperature shoulder (the desorption temperature of which is difficult to resolve). The high-temperature shoulder saturates at $\sim 6 \mathrm{~L}$ but the low-temperature state continues to grow with exposure. The $210 \mathrm{~K}$ state is thus assigned to multilayer desorption, and the high-temperature state to desorption from the monolayer. Figure $14 \mathrm{~b}$ plots the hydrogen desorption profiles where the hydrogen yield is lower than that for propylene (Figure 1b) or 1-iodopropane (Figure 9a) at similar exposures.

Figure 14c plots the 42 amu (propylene) desorption profiles as a function of DIP exposures where at exposures of $5 \mathrm{~L}$ and lower all spectra display two desorption regimes. The lowtemperature regime is assigned to fragmentation of molecular DIP, corresponding to molecular desorption shown in Figure $14 \mathrm{a}$, although the line shapes are not identical at these two masses. Presumably the mass spectrometer sensitivity drops substantially at high masses. Note, however, some desorption does occur at $42 \mathrm{amu}$ at below $200 \mathrm{~K}$, which apparently is not 


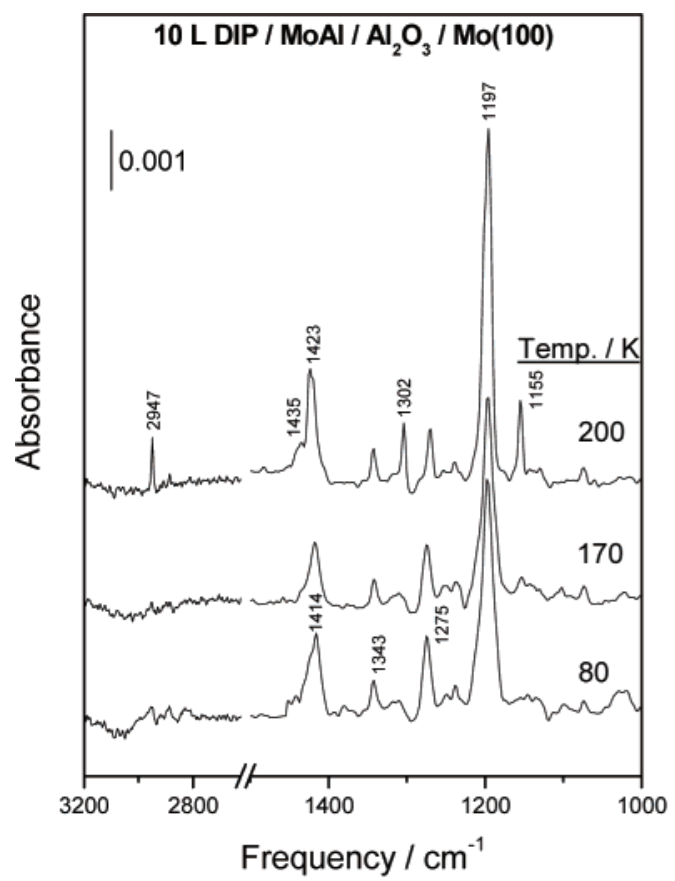

(a)

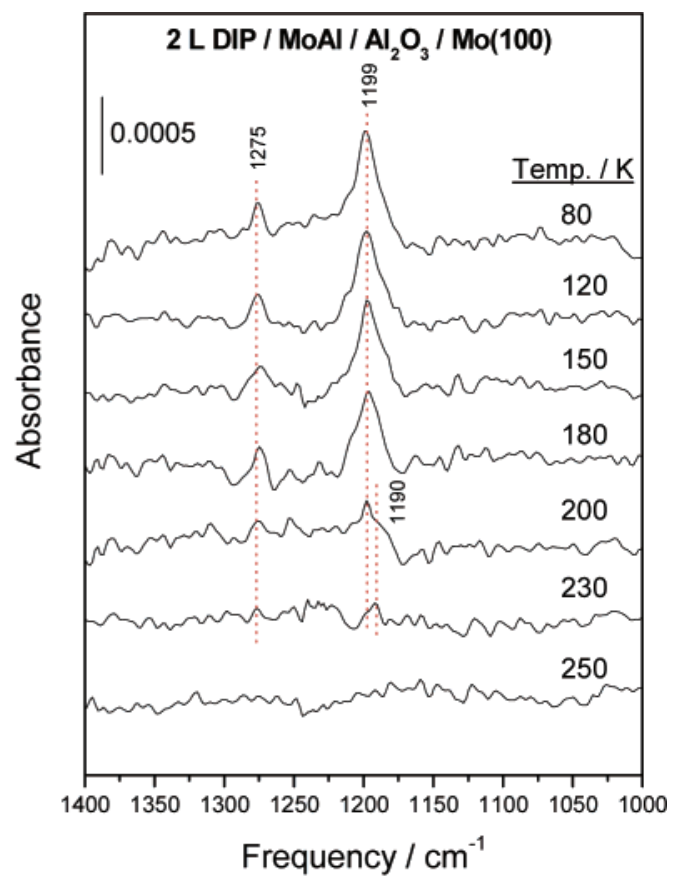

(b)

Figure 12. Reflection-absorption infrared spectra (RAIRS) following the adsorption of (a) 10 and (b) $2 \mathrm{~L}$ of 1,3-diiodopropane on a MoAl alloy as a function of annealing temperature, where the annealing temperatures are displayed adjacent to the corresponding spectrum.

associated with molecular DIP. There could be two origins of this desorption state. It could either be due to desorption of contaminants (very likely 1-iodopropane) or to 1-iodopropane formed from DIP at below $200 \mathrm{~K}$, where a small portion of DIP releases only one iodine atom and then hydrogenates. Nevertheless, this desorbs at rather low temperature so will not substantially affect high-temperature reactions on the surface. More interestingly, desorption occurs at $\sim 320 \mathrm{~K}$ at DIP exposures of $2 \mathrm{~L}$ and higher. By monitoring masses between 38 and 42 amu (data not shown) and comparing these with standard cracking patterns of $\mathrm{C}_{3}$ compounds measured with the same spectrometer, this is assigned unambiguously to propylene desorption. Note in particular that this desorption is not due to cyclopropane since the latter molecule displays a stronger 42 amu signal than that at $41 \mathrm{amu}$. Very little propane desorption (monitored at $29 \mathrm{amu}$ ) was found at $\sim 250 \mathrm{~K}$ so that the spectra are not displayed.

Methane desorption is also explored following DIP dissociation where Figure 15a plots the methane desorption as a function of DIP exposure. Methane desorbs at $\sim 280 \mathrm{~K}$, detectable even at the lowest DIP exposure where the methane yield found here is much larger than that for propylene (Figure 1c), and the desorption temperature is also substantially lower. This strongly suggests that these originate from different surface intermediates. Figure 15b displays TPD spectra collected at 26, 27, and 41 amu following the adsorption of 1,2 , and $5 \mathrm{~L}$ of DIP on the surface. For direct comparison, the desorption at these masses following the adsorption of $1 \mathrm{~L}$ of propylene is also displayed. Two key points should be noted. First, DIP dissociation results in much larger 26 and $27 \mathrm{amu}$ signals relative to that at $41 \mathrm{amu}$ when compared with propylene. Second, the 26 and $27 \mathrm{amu}$ desorption temperature is also lower than that at $41 \mathrm{amu}$, especially at a DIP exposure of $5 \mathrm{~L}$ where, at this exposure, the desorption temperature at $41 \mathrm{amu}$ is $\sim 320 \mathrm{~K}$, identical with that for pure propylene. However, the desorption temperature at 26 and $27 \mathrm{amu}$ is at $\sim 280 \mathrm{~K}$, identical with the methane desorption temperature. These data clearly indicate that ethylene is formed.

Hydrogenation of DIP is investigated on a deuterium-covered surface. In this case, 46 amu desorption was monitored to avoid any overlap with fragments of DIP and any potential contaminants. It is found from Figure 16 that two desorption states developed at every DIP exposure at $\sim 240$ and $\sim 300 \mathrm{~K}$ and are assigned, based on results shown below, to a hydrogenation product $\mathrm{C}_{3} \mathrm{H}_{6} \mathrm{D}_{2}$ and $\mathrm{H}-\mathrm{D}$ exchange product $\mathrm{C}_{3} \mathrm{H}_{2} \mathrm{D}_{4}$, respectively. Again, this assignment is not completely unambiguous because of possible overlap of propylene and propane isotopomers.

Finally, $\mathrm{H}-\mathrm{D}$ exchange reactions are performed by adsorbing 3.5 L of DIP on an alloy surface precovered with $20 \mathrm{~L}$ of $\mathrm{D}_{2}$ (Figure 17). Similar to the behavior shown in Figure 11, the 43 to 48 amu signals peak at $\sim 300 \mathrm{~K}$, and the 49 to $51 \mathrm{amu}$ signals at $\sim 280 \mathrm{~K}$. Note that no signal was detected at $52 \mathrm{amu}$. The same behavior is found by varying the $\mathrm{D}_{2}$ and DIP exposures. We again assign desorption between 43 and 48 amu to propylene isotopomers and desorption from 49 to 51 amu to propane isotopomers. Low-temperature shoulders at $\sim 240 \mathrm{~K}$ appear between 43 and 46 amu, but are absent at higher masses. This is due to hydrogenation without any $\mathrm{H}-\mathrm{D}$ exchange. The desorption peak areas from 45 to 51 amu are also plotted as an inset where for 45 and $46 \mathrm{amu}$, only the area under the hightemperature peak is included.

\section{Discussion}

4.1. Molecular Adsorption/Desorption of $C_{3}$ Species. Propylene adsorbs molecularly on the MoAl alloy surface at 80 K. RAIRS data (Figure 2) clearly demonstrate that this adopts a $\pi$-bonded conformation following a $10 \mathrm{~L}$ exposure. The presence of di- $\sigma$-bonded propylene is suggested by the presence of features at 1433 and $2923 \mathrm{~cm}^{-1}$ and di- $\sigma$-bonded propylene has been identified on a number of transition metal surfaces ${ }^{30,31}$ where $\pi$-bonded propylene desorbs below $200 \mathrm{~K}$. The diminu- 

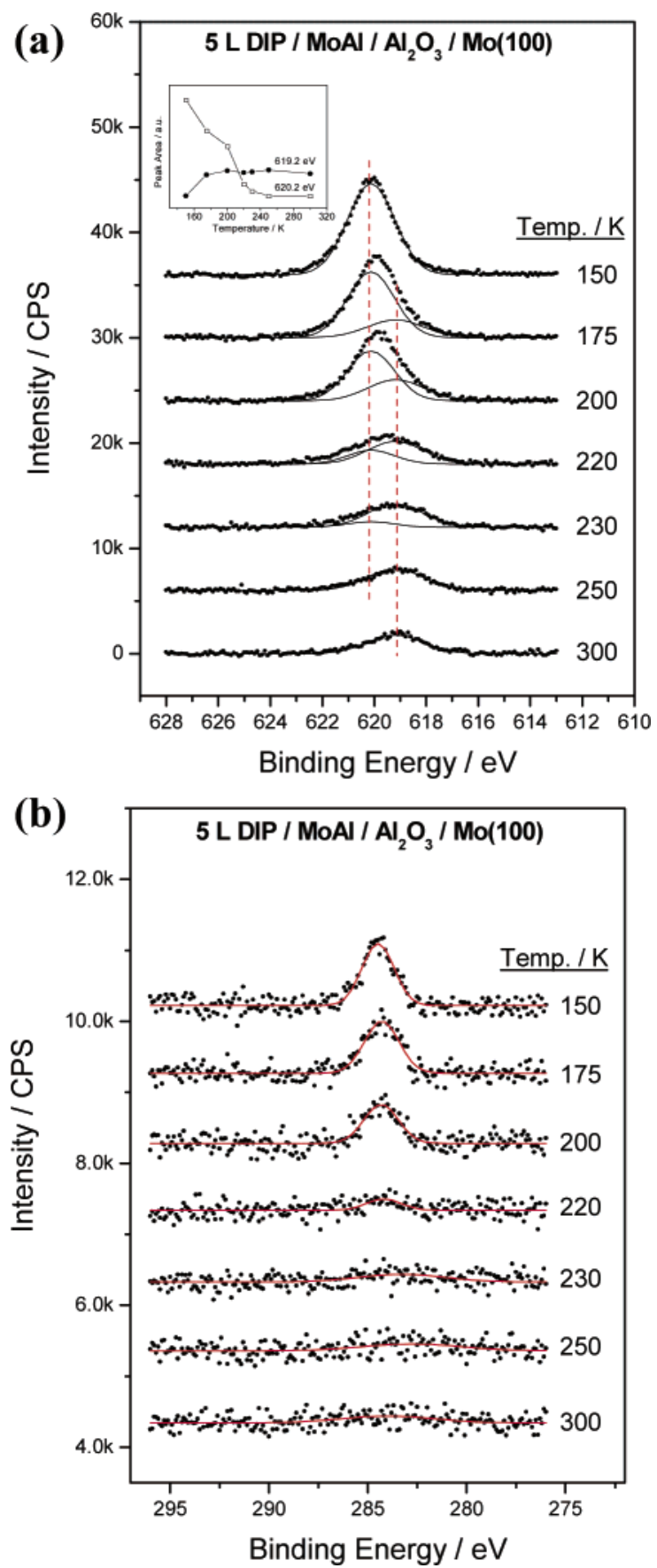

Figure 13. (a) $\mathrm{I} 3 \mathrm{~d}_{5 / 2}$ and (b) $\mathrm{C} 1 \mathrm{~s}$ photoelectron spectra of $10 \mathrm{~L}$ of 1,3-diiodopropane adsorbed on a MoAl surface at $150 \mathrm{~K}$ and heated to various temperatures, where the annealing temperatures are displayed adjacent to the corresponding spectrum. Shown as an inset are the areas of the I $3 d_{5 / 2}$ signals from 1,3-diiodopropane (centered at $620.2 \mathrm{eV}$ ) and atomic iodine (centered at $619.2 \mathrm{eV}$ ) plotted as a function of temperature.

tion of the $\mathrm{C}=\mathrm{C}$ stretching mode at $1645 \mathrm{~cm}^{-1}$ (Figure 2), as well as the TPD results shown in Figure 1a, provides evidence for a $\pi$-bonded state that desorbs at $\sim 200 \mathrm{~K}$. Thus only di- $\sigma$ bonded propylene is present on the alloy surface at $200 \mathrm{~K}$ and above and from Figure 1a desorbs at $\sim 300 \mathrm{~K}$ and is completely removed by $\sim 400 \mathrm{~K}$. It should also be mentioned that the desorption temperature of di- $\sigma$-bonded propylene decreases slightly with increasing propylene exposure, due to repulsive interactions. Such intermolecular interactions are also reflected in the RAIRS data where it is found that the relative intensities of the $1435\left(\delta\left(\mathrm{CH}_{2}\right)\right)$ and $1452 \mathrm{~cm}^{-1}\left(\delta_{\mathrm{a}}\left(\mathrm{CH}_{3}\right)\right)$ features for $\pi$-bonded propylene vary as the sample is annealed from 80 to $180 \mathrm{~K}$ suggesting methyl groups are more perpendicular to the surface at higher coverages.

RAIRS measurements show that 1-iodopropane also adsorbs molecularly on the alloy at $80 \mathrm{~K}$ (Figure 6) but no conclusions regarding $\mathrm{C}-\mathrm{I}$ bond scission and propyl group formation can be drawn from RAIRS data. XPS results, however, provided a clearer picture of when the $\mathrm{C}-\mathrm{I}$ bond cleaves where the photoelectron spectra shown in Figure 7a demonstrate that molecular desorption ceases at $\sim 220 \mathrm{~K}$ and that $\mathrm{C}-\mathrm{I}$ bonds cleave as low as $160 \mathrm{~K}$ and this process is complete by $200 \mathrm{~K}$. This corresponds rather well with TPD data shown in Figure 8 where multilayer desorption occurs at $\sim 190 \mathrm{~K}$ and monolayer desorption occurs at between 210 and $220 \mathrm{~K}$ depending on coverage. Low-temperature propane formation shown in Figures $9 \mathrm{c}$ and $10 \mathrm{c}$ proves that $\mathrm{C}-\mathrm{I}$ bonds cleave below $200 \mathrm{~K}$ (Figure 8 ), in accord with XPS data.

In the case of 1,3-diiodopropane (DIP), RAIRS reveals significant structural information, particularly regarding conformational changes at low temperatures. Bulk DIP can adopt three molecular conformations: anti-anti (AA), anti-gauche (AG), and gauche-gauche (GG), with the GG conformation having the lowest energy. ${ }^{36}$ Upon adsorption, the interaction between DIP and the surface also allows for the existence of a so-called "standing up" conformation. ${ }^{37}$ Comparing the absorbances at $80 \mathrm{~K}$ with solid DIP at $90 \mathrm{~K},{ }^{33,38}$ it is straightforward to assign these to GG conformation, as expected (Table 3). The similarity between the spectra taken at 80 and $170 \mathrm{~K}$ suggests that no drastic conformational changes occur within this temperature range. However, the new features at 1304 and 1156 $\mathrm{cm}^{-1}$ detected when the sample is annealed to $200 \mathrm{~K}$ strongly suggest that a portion of adsorbed DIP converts to an AA conformation (Table 3). Since the $1197-\mathrm{cm}^{-1}$ feature still dominates, the proportion of the AA conformer is not large. More interestingly, the intensity increase of the 1197- and 1423$\mathrm{cm}^{-1}$ features, especially the drastic increase in $2947-\mathrm{cm}^{-1}$ signal, suggests that a portion of adsorbed DIP also adopts a "standing up" conformation. Note that since the various modes of GG and "standing up" conformations are essentially identical, ${ }^{37}$ it is impossible to unambiguously distinguish these, except by comparing the relative intensities of various modes. Since these conformation changes do not profoundly affect the surface chemistry of adsorbed DIP, they will not be discussed further. Nevertheless, it was found, in accord with a previous study, where a condensed layer of DIP (20 monolayers) adsorbed on $\mathrm{Pt}(111)$ displayed similar conformational changes, ${ }^{37}$ and such changes also occur on a solid surface at much lower film thicknesses.

The XPS data shown in Figure 13 demonstrate that $\mathrm{C}-\mathrm{I}$ bond cleavage in DIP commences at $\sim 175 \mathrm{~K}$ and is complete by $200 \mathrm{~K}$, and molecular desorption occurs below $230 \mathrm{~K}$, consistent with TPD results (Figure 14a).

4.2. Dehydrogenation and Reaction of $C_{3}$ Species. By analogy with the chemistry on many late-transition-metal surfaces, the dissociation of propylene eventually results in carbon deposition on the surface and $\mathrm{H}_{2}$ evolution. However, substantial differences are noted between the chemistry on a MoAl alloy and close-packed, late transition metals. ${ }^{30,31}$ It is found that, for both normal and deuterium-substituted propylene $\left(\mathrm{C}_{3} \mathrm{D}_{6}, \mathrm{CD}_{2}=\mathrm{CH}-\mathrm{CH}_{3}\right.$, and $\left.\mathrm{CH}_{2}=\mathrm{CH}-\mathrm{CD}_{3}\right)$ at various exposures (Figures $1 \mathrm{~b}$ and 5 ), $\mathrm{H}_{2}, \mathrm{HD}$, and $\mathrm{D}_{2}$ desorb as a single broad feature between $\sim 250$ and $\sim 550 \mathrm{~K}$. This strongly suggests that no stable hydrocarbon intermediates form on the surface within this temperature range. This is in contrast to the chemistry 

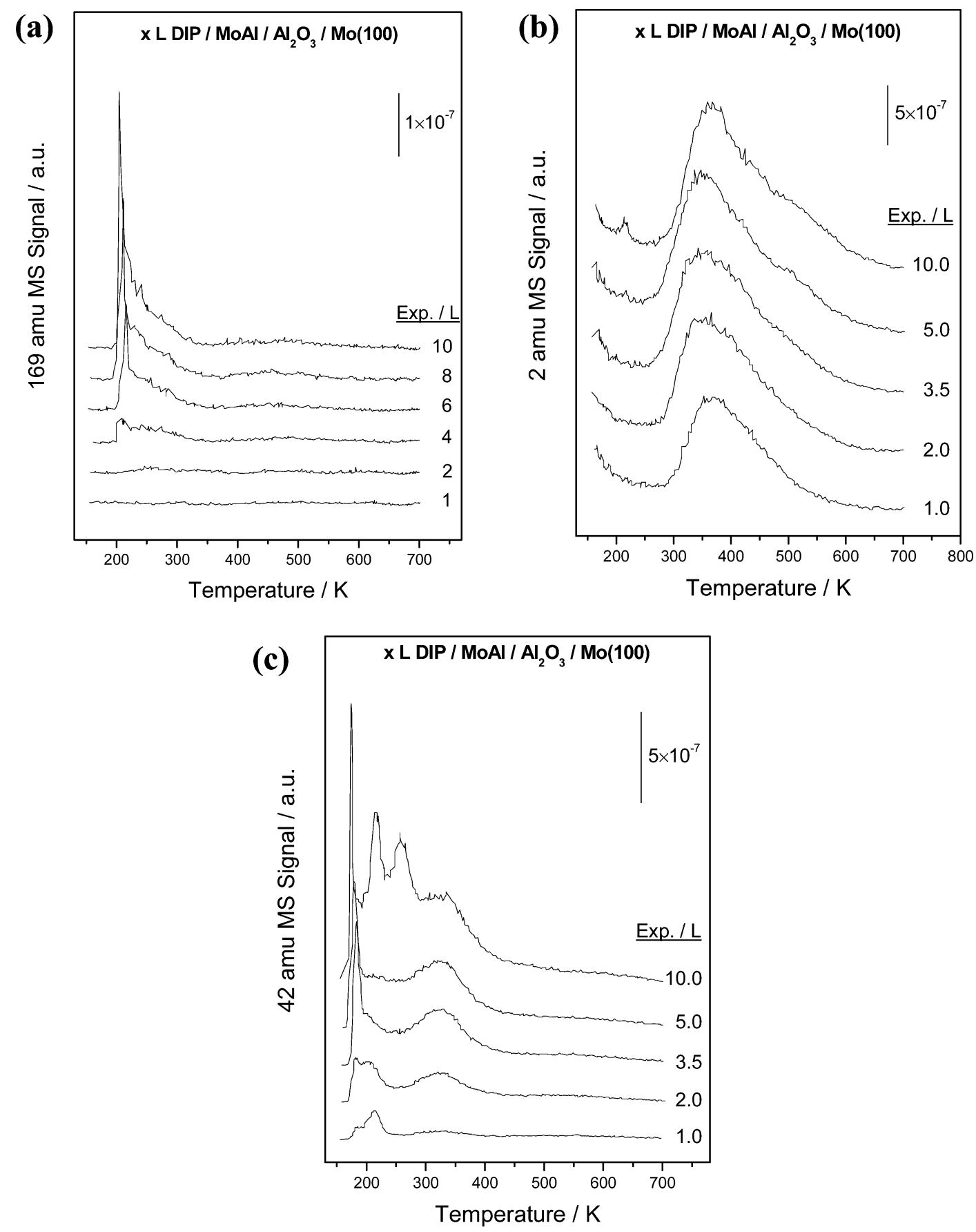

Figure 14. Temperature-programmed desorption spectra of various exposures of 1,3-diiodopropane adsorbed on a MoAl alloy surface, monitoring (a) 169 (1,3-diiodopropane), (b) 2 (hydrogen), and (c) 42 (propylene) amu. The 1,3-diiodopropane exposures are marked adjacent to the corresponding spectrum.

on close-packed, late-transition metals where hydrogen desorbs in several well-resolved states due to the formation and decomposition of propylidyne, a species that is stable even above room temperature. ${ }^{30,31}$ Nevertheless, the breadth of the hydrogen desorption state indicates that this is due to slightly different dehydrogenation kinetics of the various $\mathrm{CH}_{x}$ groups. This is explored by using different propylene isotopomers (Figure 5). First note, as emphasized above, that the hydrogen (deuterium) desorption profiles for $\mathrm{C}_{3} \mathrm{H}_{6}$ and $\mathrm{C}_{3} \mathrm{D}_{6}$ are almost identical indicating that the shift in peak position due to kinetic isotope effects is only $\sim 6 \mathrm{~K}$. Deuterium desorbs from $\mathrm{CH}_{2}=\mathrm{CH}-\mathrm{CD}_{3}$ at $\sim 435 \mathrm{~K}$ indicating that methyl group dehydrogenation occurs at approximately this temperature. A simple Redhead analysis, ${ }^{39}$ assuming that dehydrogenation occurs as a first-order process with a preexponential factor of $\sim 10^{13} \mathrm{~s}^{-1}$, yields a corresponding activation energy of $\sim 110 \mathrm{~kJ} / \mathrm{mol}$. Similarly, deuterium from $\mathrm{CD}_{2}=\mathrm{CH}-\mathrm{CH}_{3}$ desorbs at $\sim 379 \mathrm{~K}$, corresponding to a slightly lower activation energy for methylene dehydrogenation of $\sim 96$ $\mathrm{kJ} / \mathrm{mol}$. The lower temperature hydrogen (2 amu) desorption state implies that the hydrogen in the $=\mathrm{CH}-$ group cleaves below $\sim 326 \mathrm{~K}$, with an activation energy of less than $75 \mathrm{~kJ} /$ mol. The ordering of these energies is completely different from the $\mathrm{C}-\mathrm{H}$ bond strength in gas-phase propylene. ${ }^{40}$ However, the decomposing propylene is di- $\sigma$-bonded on the alloy surface and the methylene $\mathrm{C}-\mathrm{H}$ bonds are weaker than those in the methyl groups in propylene (412 versus $423 \mathrm{~kJ} / \mathrm{mol}^{40}$ ). The additional stability of the methyl groups is likely to be due to steric effects since it is farther away from the surface. Note also that small amounts of methane form at $\sim 325-350 \mathrm{~K}$ following propylene adsorption (Figure 1c) but no ethylene formation is detected 

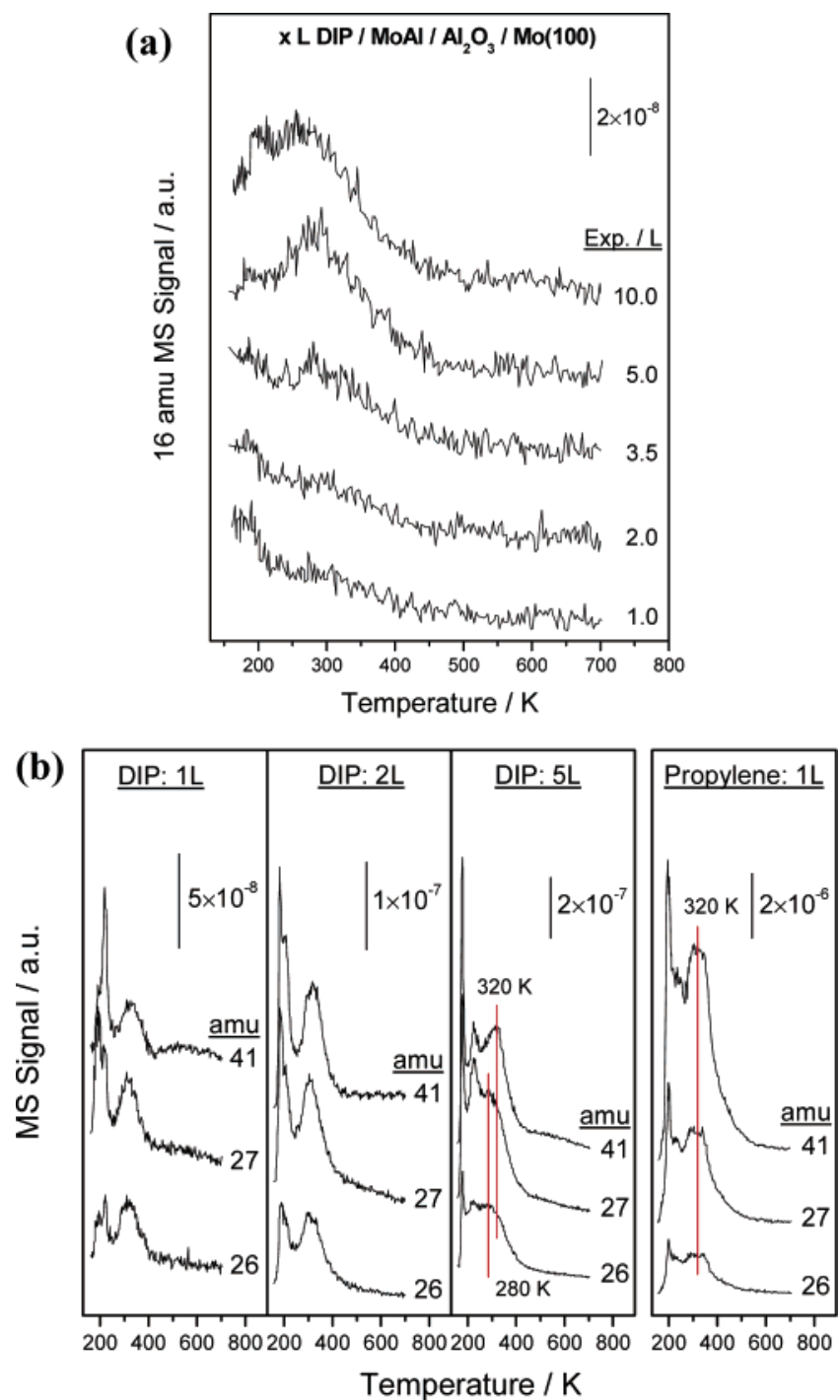

Figure 15. Temperature-programmed desorption spectra of various exposures of 1,3-diiodopropane adsorbed on a MoAl alloy surface, monitoring (a) 16 (methane), (b) 41 (propylene), and 26 and 27 (ethylene) amu. The 1,3-diiodopropane exposures are marked adjacent to the corresponding spectrum.

(Figure 15b, right column). These results are consistent with the following reaction pathway: first hydrogen in the $\mathrm{CH}$ and $\mathrm{CH}_{2}$ groups is released and the resulting intermediate undergoes carbon-carbon bond cleavage, accompanied by additional $\mathrm{C}-\mathrm{H}$ bond scission to generate surface $\mathrm{CH}_{x}$ species. Further decomposition of the latter species results in the formation of atomic carbon or they can hydrogenate to yield small amounts of methane. The slightly higher desorption temperature of methane at the highest propylene exposure (Figure 1c) suggests that at low exposures propylene bonds stronger with the surface so that $\mathrm{CH}_{x}$ species are generated at lower temperatures.

The first reaction step in 1-iodopropane decomposition is $\mathrm{C}-\mathrm{I}$ bond cleavage. This has been observed repeatedly on various surfaces, due to the much lower bond strength of the $\mathrm{C}-\mathrm{I}$ bond compared to $\mathrm{C}-\mathrm{C}$ or $\mathrm{C}-\mathrm{H}$ bonds. ${ }^{41,42}$ Even though no information regarding the formation of propyl species can be obtained from RAIRS experiments (Figure 6), XPS results indicate that this process is complete by $\sim 200 \mathrm{~K}$ (Figure 7 ). The main $\mathrm{C}_{3}$ reaction product from the resulting propyl species is propylene (Figure 9b), formed by $\beta$-hydride elimination. Some additional comments concerning propylene desorption are warranted. First, at low 1-iodopropane exposures, propylene desorbs at $\sim 300$

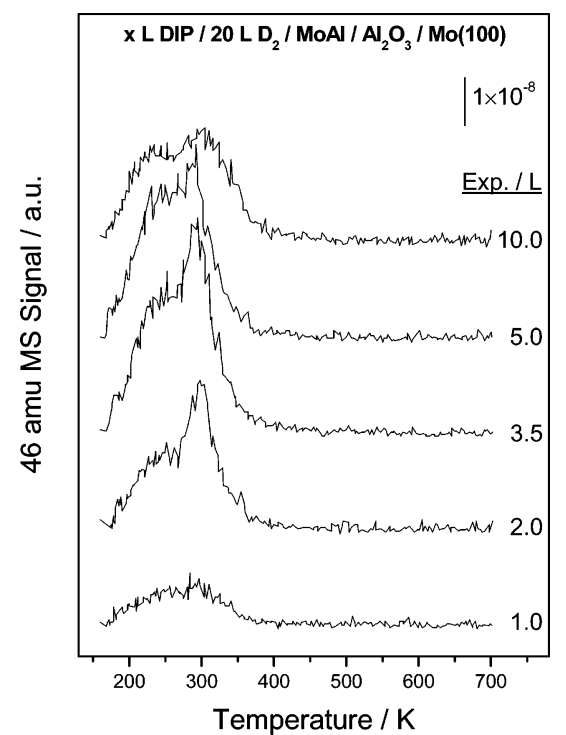

Figure 16. Temperature-programmed desorption spectra of various exposures of 1,3-diiodopropane adsorbed on an alloy surface precovered by $20 \mathrm{~L}$ of $\mathrm{D}_{2}$, monitoring $46 \mathrm{amu}$ (propane). The 1,3-diiodopropane exposures are marked adjacent to the corresponding spectrum.

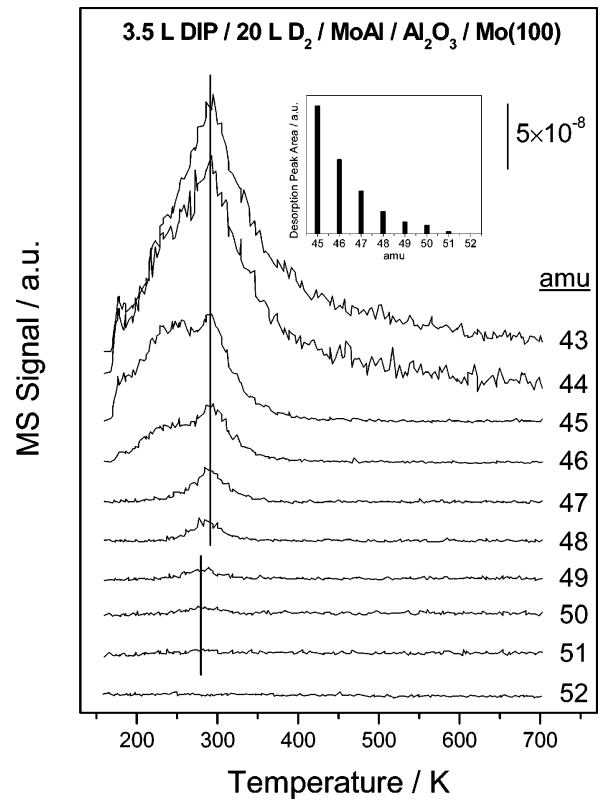

Figure 17. Temperature-programmed desorption spectra of $3.5 \mathrm{~L}$ of 1,3-diiodopropane adsorbed on an alloy surface precovered by $20 \mathrm{~L}$ of $\mathrm{D}_{2}$, monitoring 43 to $52 \mathrm{amu}$. Shown as an inset is a plot of the desorption yield as a function of mass.

$\mathrm{K}$, a temperature similar to desorption of pure propylene from the surface (Figure 1a). Presumably propylene desorption in this case is desorption-rate limited, where the propyl intermediate undergoes rapid $\beta$-hydride elimination to generate di- $\sigma$-bonded propylene below its desorption temperatures. Second, at high 1-iodopropane exposures $(>3.5 \mathrm{~L})$, in addition to this desorption state, another high-temperature reaction channel develops on the surface also leading to propylene desorption at $\sim 380 \mathrm{~K}$. The low-temperature shoulder (Figure 9b) at high 1-iodopropane exposures is likely to be due to fragmentation of the parent molecule suggesting the surface has become crowded. It is reasonable to suggest that, at low iodopropane exposures, sufficient vacant sites are present on the surface to allow facile $\beta$-hydride elimination reactions to occur. In contrast, on a crowded surface, the $\beta$-hydride elimination reaction requires the 
TABLE 3: Assignments of the RAIRS Spectra Obtained Following the Adsorption of DIP on MoAll Alloy Surfaces

\begin{tabular}{|c|c|c|c|c|}
\hline $\begin{array}{l}\text { solid DIP } \\
\text { at } 90 \mathrm{~K}^{a}\end{array}$ & $\begin{array}{l}\text { DIP under } \\
20 \mathrm{kbar}^{a}\end{array}$ & $\begin{array}{c}10 \mathrm{~L} \text { DIP/ } \\
\text { alloy at } 80 \mathrm{~K}^{b}\end{array}$ & $\begin{array}{c}10 \mathrm{~L} \text { DIP/ } \\
\text { alloy at } 200 \mathrm{~K}^{b}\end{array}$ & assignment $^{c}$ \\
\hline 1418 & & 1414 & 1419 & $\mathrm{GG}, \gamma\left(\alpha-\mathrm{CH}_{2}\right)$ \\
\hline 1338 & & 1343 & 1342 & $\mathrm{GG}, \omega\left(\beta-\mathrm{CH}_{2}\right)$ \\
\hline 1270 & & 1275 & 1270 & $\mathrm{GG}, \omega\left(\alpha-\mathrm{CH}_{2}\right)$ \\
\hline 1197 & & 1197 & 1196 & $\mathrm{GG}, \tau\left(\alpha-\mathrm{CH}_{2}\right)$ \\
\hline & 1435 & & 1435 & $\mathrm{AA}, \gamma\left(\beta-\mathrm{CH}_{2}\right)$ \\
\hline & 1424 & & 1423 & $\mathrm{AA}, \gamma\left(\alpha-\mathrm{CH}_{2}\right)$ \\
\hline & 1415 & & & $\mathrm{AA}, \gamma\left(\alpha-\mathrm{CH}_{2}\right)$ \\
\hline & 1304 & & 1304 & $\mathrm{AA}, \gamma\left(\alpha-\mathrm{CH}_{2}\right)$ \\
\hline & 1231 & & 1238 & $\mathrm{AA}, \omega\left(\beta-\mathrm{CH}_{2}\right)$ \\
\hline & 1204 & & & $\mathrm{AA}, \omega\left(\alpha-\mathrm{CH}_{2}\right)$ \\
\hline & 1154 & & 1155 & $\mathrm{AA}, \tau\left(\alpha-\mathrm{CH}_{2}\right)$ \\
\hline
\end{tabular}

${ }^{a}$ Taken from ref $38 .{ }^{b}$ This work. ${ }^{c} \gamma$, scissoring; $\omega$, wagging; $\tau$, twisting; $\alpha$, end methylene; $\beta$, center methylene.

desorption of propylene to create vacant sites for hydrogen, resulting in the additional high-temperature propylene desorption state.

On a $\mathrm{H}_{2}$-precovered surface, subtle differences regarding these two desorption states are observed (Figure 10b). First surface hydrogen may modify the geometry of surface propyl species to some extent and the $\mathrm{H}_{2}$ desorption profiles presented in Figure 9 a provide evidence in support of this suggestion. At 1-iodopropane exposures between 0.5 and $3.5 \mathrm{~L}$, the hydrogen desorption temperature decreases and the yield increases suggesting that the $\beta$-hydride elimination step is not hindered. At higher iodopropane exposures ( $5 \mathrm{~L}$ and above), the $\mathrm{H}_{2}$ desorption profiles become sharper at temperatures close to the hightemperature desorption state of propylene. This clearly indicates rapid hydrogen combination immediately following $\beta$-hydride elimination, which then becomes the rate-limiting step for hydrogen formation on a crowded surface. It should be pointed out that no methane or ethylene formation has been detected following 1-iodopropane adsorption.

Carbon is deposited onto the alloy surface following 1-iodopropane adsorption at low temperatures and after annealing to $\sim 750 \mathrm{~K}$. Due to the low XPS cross-section for carbon, this is not detected spectroscopically (Figure 7b). However, Auger measurements after heating to $750 \mathrm{~K}$ clearly detected carbon, suggesting a portion of propyl-derived species decomposes completely.

XPS measurements indicate that $\mathrm{C}-\mathrm{I}$ bond cleavage of adsorbed DIP occurs below $220 \mathrm{~K}$ (Figure 13), at a temperature similar to that for 1-iodopropane (Figure 7). It is impossible to determine, however, whether $\mathrm{C}-\mathrm{I}$ bonds cleave concurrently or sequentially for DIP molecules from the XPS data. However, the low-temperature desorption signal at 42 amu shown in Figure $14 \mathrm{c}$, likely due to fragmentation of 1-iodopropane, suggests that $\mathrm{C}-\mathrm{I}$ bonds may cleave sequentially. ${ }^{43}$ Again, although RAIRS results provide no strong evidence for the formation of $\mathrm{C}_{3}$ metallacycle species on the surface following $\mathrm{C}-\mathrm{I}$ bond scission (although a shoulder at $1190 \mathrm{~cm}^{-1}$ at $200 \mathrm{~K}$ (Figure 12b) may be due to a methylene twisting mode of $\mathrm{C}_{3}$ metallacycle), the fact that DIP adopts a GG conformation on the surface, at least at low exposures, and that $\mathrm{C}-\mathrm{I}$ bonds cleave at rather low temperatures (Figure 13), strongly suggests that $C_{3}$ metallacycle species are formed on the surface at above $200 \mathrm{~K}$. As will be shown below, this is well supported by other evidence.

The data shown in Figure 14c demonstrate that propylene forms at $\sim 320 \mathrm{~K}$ following the formation of $\mathrm{C}_{3}$ metallacycles. The conversion of $\mathrm{C}_{3}$ metallacycles to propylene has been suggested previously by Zaera et al. ${ }^{43}$ to involve $\eta^{3}$-allylic intermediates, where $\mathrm{C}_{3}$ metallacycle first dehydrogenates to form $\eta^{3}$-allylic species and the latter species hydrogenate to form di- $\sigma$-bonded propylene. However, another decomposition pathway is found for $\mathrm{C}_{3}$ metallacycle species on the MoAl alloy. The data shown in Figure 15a reveal methane formation at $\sim 280$ $\mathrm{K}$ where the methane yield in this case is substantially higher than that from either propylene (Figure 1c) or ethylene. ${ }^{22}$ In addition, the desorption temperature is also substantially lower than that in the latter cases (Figure 1c). In fact, this methane desorption temperature is rather close to that due to methylene hydrogenation when formed from $\mathrm{CH}_{2} \mathrm{I}_{2}$ on the same surface. ${ }^{21}$ Figure $15 \mathrm{~b}$ compares the desorption profiles at 26, 27, and 41 amu following DIP adsorption and those for propylene at these masses. The much higher yields of 26 and $27 \mathrm{amu}$ following DIP dissociation immediately suggest that ethylene is formed. Note especially that at a DIP exposure of $5 \mathrm{~L}$, ethylene desorbs at $\sim 280 \mathrm{~K}$, lower than the propylene desorption temperature, yet identical with the desorption temperature of methane. These results provide rather strong evidence for $\mathrm{C}_{3}$ metallacycle formation from DIP and furthermore indicate that the $\mathrm{C}_{3}$ metallacycle dissociates by $\mathrm{C}-\mathrm{C}$ bond scission, to form surface methylene species and ethylene at $280 \mathrm{~K}$ or below, and that the methylene species hydrogenate rapidly to form methane at $\sim 280 \mathrm{~K}$. The remaining $\mathrm{C}_{3}$ metallacycles undergo $\beta$-hydride elimination to form surface $\eta^{3}$-allylic species, which eventually hydrogenate to propylene and desorb at $\sim 320 \mathrm{~K}$. To the best of our knowledge, this is the first direct experimental evidence for the decomposition of $\mathrm{C}_{3}$ metallacycle species to form methylene and ethylene on a surface in ultrahigh vacuum.

4.3. Hydrogenation of $\mathbf{C}_{3}$ Species. Self-hydrogenation of propylene occurs at $\sim 260 \mathrm{~K}$ (Figure 1d) where hydrogen originates from background adsorption and propylene dissociation. Since $\pi$-bonded propylene desorbs below $\sim 200 \mathrm{~K}$, it is rather clear that the $260 \mathrm{~K}$ propane desorption state originates from the hydrogenation of di- $\sigma$-bonded propylene. However, a low-temperature 29 amu state is detected at high propylene exposures. It appears that this is due completely to fragmentation of $\pi$-bonded propylene as evidenced by the data shown in Figure 3 , where no low-temperature propane formation was found. Figure 3 also demonstrates that propane formation is limited by the availability of surface hydrogen (deuterium).

In contrast to the hydrogenation of propylene, two propane formation states are found for 1-iodopropane hydrogenation (Figures 9c and 10c). A sharp propane desorption state is found at below $200 \mathrm{~K}$ on both bare and $\mathrm{H}_{2}$-precovered surfaces where the propane yield is higher on the $\mathrm{H}_{2}$-precovered surface. It could be argued that this low-temperature desorption state could be due to the fragmentation of 1-iodopropane or $\mathrm{CO}_{2}$ contaminants, but a similar feature at 45 amu (due to $\mathrm{C}_{3} \mathrm{H}_{7} \mathrm{D}$ ) from a $\mathrm{D}_{2}$-precovered surface (Figure 11) immediately excludes these possibilities. A second propane desorption state is centered at $\sim 250 \mathrm{~K}$ and the yield of this state is also much higher on hydrogen-precovered surfaces. On a crowded surface, some propane also forms at even higher temperature (Figures 9c and 10c) and this is likely to be due to hydrogenation of the portion of intact propyl species that had not yet dehydrogenated because of surface crowding.

The hydrogenation of surface propyl species provides a clearer picture of the propylene hydrogenation pathway. It appears that initial addition of hydrogen to propylene to form a surface propyl intermediate is the rate-limiting step in the propane formation reaction. Once the propyl species has been formed, the second hydrogen addition proceeds rapidly.

Surface $\mathrm{C}_{3}$ metallacycle species also hydrogenate to form propane. Unlike in the case of 1-iodopropane, where facile 
$\beta$-hydride elimination of propyl species provides the requisite hydrogen, only a small amount of propane is formed on a bare surface from DIP. One possibility is that $C_{3}$ metallacycles do not easily undergo $\beta$-hydride elimination, or that DIP adsorption effectively blocks hydrogen adsorption. This argument is partly proved by smaller $\mathrm{H}_{2}$ yield from DIP dissociation (Figure 14b) than from propylene (Figure 1b) and 1-iodopropane (Figure 9a). Nevertheless, on a deuterium-covered surface, propane $\left(\mathrm{C}_{3} \mathrm{H}_{6} \mathrm{D}_{2}\right)$ desorption is indeed found at temperatures slightly below 250 $\mathrm{K}$ (Figure 16). Again, this provides additional strong evidence for the existence of $\mathrm{C}_{3}$ metallacycle species on the surface. The likely reaction pathway is the initial addition of hydrogen to the $\mathrm{C}_{3}$ metallacycle to form propyl species, which then rapidly hydrogenate to form propane. As will be shown below, the $\sim 300$ $\mathrm{K}$ desorption state at $46 \mathrm{amu}$ is assigned to desorption of the $\mathrm{H}-\mathrm{D}$-exchanged product, $\mathrm{C}_{3} \mathrm{H}_{2} \mathrm{D}_{4}$.

4.4. $\mathbf{H}-\mathrm{D}$ Exchange of $\mathrm{C}_{3}$ Species. $\mathrm{H}-\mathrm{D}$ exchange is closely related to hydrogenation and, in many cases, provides unique and useful information on hydrocarbon conversion reactions. . $^{32,43-46}$ Results shown in Figure 4a demonstrate that deuteriumsubstituted propane desorbs at $\sim 260 \mathrm{~K}$ and this result correlates rather well with Figure 4b. Unfortunately in Figure 4b, it is not possible to unambiguously assign the desorption states between 43 and $48 \mathrm{amu}$ (that is, whether these are due to propylene or propane isotopomers), because no apparent desorption temperature differences are evident. However, desorption at $52 \mathrm{amu}$ $\left(\mathrm{C}_{3} \mathrm{D}_{8}\right)$ clearly indicates all propylene isotopomers up to $\mathrm{C}_{3} \mathrm{D}_{6}$ are formed on the surface. The desorption temperature of propylene and propane isotopomers also suggests that only di$\sigma$-bonded propylene undergoes $\mathrm{H}-\mathrm{D}$ exchanges, in accord with previous studies on $\mathrm{Pt}(111){ }^{32}$

In contrast to propylene, the assignments of $\mathrm{H}-\mathrm{D}$ exchange products with 1-iodopropane (Figure 11) and DIP (Figure 17) are relatively straightforward. The desorption temperature for masses between 49 and 52 amu (due to propane isotopomers) is $\sim 20 \mathrm{~K}$ lower than that for masses at 48 amu and below. This allows masses at $48 \mathrm{amu}$ and below to be assigned mainly to propylene isotopomers, considering the fact that propylene desorbs at higher temperatures than for propane from 1-iodopropane (Figure 9) and DIP (Figures 14c and 16), and that $\mathrm{H}-\mathrm{D}$ exchange steps are generally fast.

A U-shaped isotope distribution is found following $\mathrm{H}-\mathrm{D}$ exchange of propylene (Figure 4b). It is expected that the yields of the final products should display an exponential decrease as the degree of substitution increases. ${ }^{32}$ This is not the case for propylene but true for 1-iodopropane (Figure 11) and DIP (Figure 17). Such a situation is relatively rare. However, similar behavior has been found previously following exchange of methyl species with deuterium in $\mathrm{UHV}^{47}$ and ethane exchange reaction with deuterium at high pressures. ${ }^{48}$ Another issue with $\mathrm{H}-\mathrm{D}$ exchange reactions is that $\mathrm{C}_{3} \mathrm{D}_{8}$ is formed from propylene and 1-iodopropane, but not from DIP.

In principle, two mechanisms could explain the observed $\mathrm{H}-\mathrm{D}$ exchange products. In the case of propylene, if $\mathrm{H}-\mathrm{D}$ exchange is initiated by a hydrogenation step, exchange will proceed by fast propyl-propylene-propyl interconversion steps, as proposed by Zaera et al. ${ }^{32,43}$ This process allows for the formation of all possible propylene and propane isotopomers as found experimentally for propylene (Figure 4) and 1-iodopropane (Figure 11). Alternatively, reaction could be initiated by a dehydrogenation step (so involves allylic intermediates) and therefore would proceed by allyl-propylene-allyl steps. As emphasized previously, ${ }^{32}$ interconversion between adsorbed propylene and allylic species could account for the exchange of all terminal hydrogen atoms, but does not explain exchange of the hydrogen at the 2-position and allows the formation of propane isotopomers with at most 7 deuterium atoms as found for DIP (Figure 17). In cases of propylene (Figure 4) and 1-iodopropane (Figure 11), since $\mathrm{C}_{3} \mathrm{D}_{8}$ is formed, propylpropylene-propyl interconversion steps must be involved. In the case of DIP, the situation is more complicated. First, the dehydrogenation of $\mathrm{C}_{3}$ metallacycle ( $\eta^{3}$-allylic species formation) appears to be irreversible, since hydrogenation products only up to 46 amu $\left(\mathrm{C}_{3} \mathrm{H}_{6} \mathrm{D}_{2}\right)$ are formed at $\sim 240 \mathrm{~K}$ (Figure 17). This notion is corroborated by previous findings on Pt(111). ${ }^{43}$ This indicates that $\mathrm{H}-\mathrm{D}$ exchange reactions do not involve $\mathrm{C}_{3}$ metallacycle species. Second, the lack of $\mathrm{C}_{3} \mathrm{D}_{8}$ formation in the DIP case (Figure 17) may suggest $\mathrm{H}-\mathrm{D}$ exchange proceeds through allyl-propylene-allyl interconversions. However, it is rather difficult to rule out the involvement of propyl species, considering the close similarity in desorption temperature and relative yields of propylene and propane isotopomers for 1-iodopropane (Figure 11) and DIP (Figure 17). Since all these reactions occur within a rather narrow temperature range, a conclusive picture cannot be drawn.

\section{Conclusions}

The chemistry of $\mathrm{C}_{3}$ hydrocarbons, namely propylene, 1-iodopropane, and 1,3-diiodopropane, has been studied in ultrahigh vacuum on a thin MoAl alloy film grown by reaction between $\mathrm{Mo}(\mathrm{CO})_{6}$ and an alumina layer grown on a $\mathrm{Mo}(100)$ singlecrystal substrate. XPS shows that $\mathrm{C}-\mathrm{I}$ bond cleavage is complete by $\sim 200 \mathrm{~K}$, depositing the corresponding hydrocarbon fragment. Propylene adopts either a $\pi$ - or di- $\sigma$-bonded configuration where the former desorbs at $\sim 200 \mathrm{~K}$ and the latter at $\sim 300 \mathrm{~K}$. The methylene and methylyne $\mathrm{C}-\mathrm{H}$ bonds cleave prior to the methyl $\mathrm{C}-\mathrm{H}$ bonds where the resulting intermediates decompose to yield carbon, and evolve hydrogen and a small amount of methane. Propylene hydrogenates to form propane via a propyl intermediate, where the addition of hydrogen to form propyl species is slower than the subsequent hydrogenation step to yield propane. In addition to hydrogenating, the propyl intermediate can decompose via a $\beta$-hydride elimination reaction to form propylene.

The metallacyclic intermediate formed from 1,3-diiodopropane can also hydrogenate to propane via a propyl species or decompose to form propylene via an allylic intermediate. However, it is also found to decompose by $\mathrm{C}-\mathrm{C}$ bond cleavage to desorb ethylene and form methylene species on the surface, which hydrogenate to yield methane. This is one of the steps in the reaction pathway proposed for olefin metathesis by Hérisson and Chauvin ${ }^{23}$ where the metallacycle is formed by methylene insertion into the $\mathrm{C}$-metal bond of ethylene and metathesis products are formed by the reverse of this reaction. This is the first time, to our knowledge, that this pathway has been directly identified on a surface.

Acknowledgment. We gratefully acknowledge support of this work by the Chemistry Division of the National Science Foundation under grant No. CTS-0105329. One of us (Y.W.) would like to acknowledge receipt of a Dissertation Fellowship from the University of Wisconsin-Milwaukee.

\section{References and Notes}

(1) Brenner, A. J. Mol. Catal. 1979, 5, 157

(2) Davie, E.; Whan, D. A.; Kemball, C. J. Catal. 1972, 24, 272.

(3) Smith, J.; Howe, R. F.; Whan, D. A. J. Catal. 1974, 34, 191.

(4) Thomas, R.; Moulijn, J. A. J. Mol. Catal. 1982, 15, 157.

(5) Brenner, A.; Burwell, R. L., Jr. J. Am. Chem. Soc. 1975, 97, 2565. 
(6) Brenner, A.; Burwell, R. L., Jr. J. Catal. 1978, 52, 353.

(7) Howe, R. F. Inorg. Chem. 1976, 15, 486.

(8) Kazusaka, A.; Howe, R. F. J. Mol. Catal. 1980, 9, 183.

(9) Reddy, K. P.; Brown, T. L. J. Am. Chem. Soc. 1995, 117, 2845.

(10) Zecchina, A.; Platero, E. E.; Areán, C. O. Inorg. Chem. 1988, 27, 102.

(11) Howe, R. F.; Leith, I. R. J. Chem. Soc., Faraday Trans. 11973 69, 1967.

(12) Shirley, W. M.; McGarvey, B. R.; Maiti, B.; Brenner, A.; Cichowlas, A. J. Mol. Catal. 1985, 29, 259.

(13) Kaltchev, M.; Tysoe, W. T. J. Catal. 2000, 193, 29

(14) Kaltchev, M.; Tysoe, W. T. J. Catal. 2000, 196, 40

(15) Wang, Y.; Gao, F.; Kaltchev, M.; Stacchiola, D.; Tysoe, W. T. Catal. Lett. 2003, 91, 83 .

(16) Wang, Y.; Gao, F.; Kaltchev, M.; Tysoe, W. T. J. Mol. Catal. A: Chem. 2004, 209, 135.

(17) Wang, Y.; Gao, F.; Tysoe, W. T. J. Mol. Catal. A: Chem. 2005, 226,18

(18) Wang, Y.; Gao, F.; Tysoe, W. T. J. Mol. Catal. A: Chem. 2005 225,173 .

(19) Wang, Y.; Gao, F.; Tysoe, W. T. J. Mol. Catal. A: Chem. 2006, 248,32 .

(20) Wang, Y.; Gao, F.; Tysoe, W. T. Surf. Sci. 2005, 590, 181

(21) Wang, Y.; Gao, F.; Tysoe, W. T. J. Phys. Chem. B 2005, 109 , 15497.

(22) Gao, F.; Wang, Y.; Burkholder, L.; Tysoe, W. T. Surf. Sci. 2006, $600,1837$.

(23) Chauvin, Y.; Hérisson, J.-L. Makromol. Chem. 1971, 141, 161.

(24) Siaj, M.; McBreen, P. H. Science, 2005, 309, 588.

(25) Wytenburg, W. J.; Lambert, R. M. J. Vac. Sci. Technol. A 1992, 10,3597 .
(26) Brüesch, C.; Kötz, R.; Neff, N.; Pietronero, L. Phys. Rev. B 1984, 29, 4691 .

(27) Kaltchev, M.; Tysoe, W. T. Surf. Sci. 1999, 430, 29.

(28) Wilson, E. B., Jr.; Wells, A. J. J. Chem. Phys. 1941, 9, 319.

(29) Comeford, J. J.; Gould, J. H. J. Mol. Spectrosc. 1960, 5, 474.

(30) Stacchiola, D.; Burkholder, L.; Tysoe, W. T. Surf. Sci. 2003, 542, 129.

(31) Zaera, F.; Chrysostomou, D. Surf. Sci. 2000, 457, 71.

(32) Zaera, F.; Chrysostomou, D. Surf. Sci. 2000, 457, 89.

(33) Crowder, G. A.; Ali, S. J. Mol. Struct. 1975, 25, 377.

(34) Tanabe, K.; Saëki, S. J. Mol. Struct. 1975, 27, 79.

(35) Jenks, C. J.; Bent, B. E.; Bernstein, N.; Zaera, F. J. Am. Chem. Soc. 1993, 115, 308.

(36) Postmyr, L. J. Mol. Struct. 1994, 319, 211.

(37) French, C. R.; Zaera, F. Chem. Phys. Lett. 1999, 309, 321.

(38) Thorbjørnsrud, J.; Ellestad, O. H.; Kalboe, P.; Torgrimsen, T. J. Mol. Struct. 1973, 15, 61 .

(39) Redhead, P. A. Vacuum 1962, 12, 203.

(40) NIST Chemistry WebBook, http://webbook.nist.gov/chemistry/.

(41) Zaera, F. Chem. Rev. 1995, 95, 2651.

(42) Bent, B. E. Chem. Rev. 1996, 96, 1361

(43) Chrysostomou, D.; Chou, A.; Zaera, F. J. Phys. Chem. B 2001, $105,5968$.

(44) Burke, M. L.; Madix, R. J. J. Am. Chem. Soc. 1991, 113, 4151.

(45) Scoggins, T. B.; White, J. M. J. Phys. Chem. B 1997, 101, 7958

(46) Chrysostomou, D.; Zaera, F. J. Phys. Chem. B 2001, 105, 1003.

(47) Zaera, F. Acc. Chem. Res. 1992, 25, 260.

(48) Zaera, F.; Somorjai, G. A. J. Phys. Chem. 1985, 89, 3211. 